


\section{¿Interpretar el patrimonio histórico? El centro de visitantes de la Puerta de Córdoba de Carmona}

Antonio Tejedor Cabrera,

Mercedes Linares Gómez del Pulgar, arquitectos

\section{Resumen}

Desarrollada en dos fases bien diferenciadas en objetivos y tiempos, la intervención en la Puerta de Córdoba de Carmona va más allá de la recuperación material de la antigua puerta romana de la ciudad (siglo I d. de C.). Victima de un sinfín de avatares que la fueron menoscabando, fue revestida a finales del siglo XVIII por una piel neoclásica que protege parte de la estructura romana original y le confiere su imagen actual.

La primera fase estuvo centrada en la restauración del monumento. El Instituto Andaluz del Patrimonio Histórico realizó los estudios previos de carácter científico-técnico y la investigación histórica en dos campañas arqueológicas. La segunda fase permitió acometer la creación del centro de visitantes Puerta de Córdoba que perseguía dos objetivos tan importantes como la propia restauración: por un lado, presentar al visitante los restos exhumados de la parte meridional para completar una lectura patrimonial del monumento con su complejo devenir, tan ligado a la historia de Carmona, y, por otro, disponer de un acceso al ático y las terrazas altas del monumento para desligarlo así definitivamente de la casa anexa.

La reflexión general sobre el modo de presentar los edificios históricos en su contexto urbano y paisajístico se centra en las dificultades de la interpretación y en la utilidad de la arquitectura para potenciar una musealización que restituya unidad de conjunto a la dispersión de los fragmentos y facilite al visitante el reconocimiento sensible de las cosas.

\section{Palabras clave}

Carmona (Sevilla) / Centro de visitantes / Interpretación /

Monumentos / Musealización / Patrimonio inmueble /

Proyectos / Puerta de Córdoba / Puertas de muralla /

Puesta en valor 
Frente a la sobreabundancia de
discursos interpretativos, el silencio

se revela como el auténtico idioma

de los monumentos y la intervención

sutil como la celebración del silencio

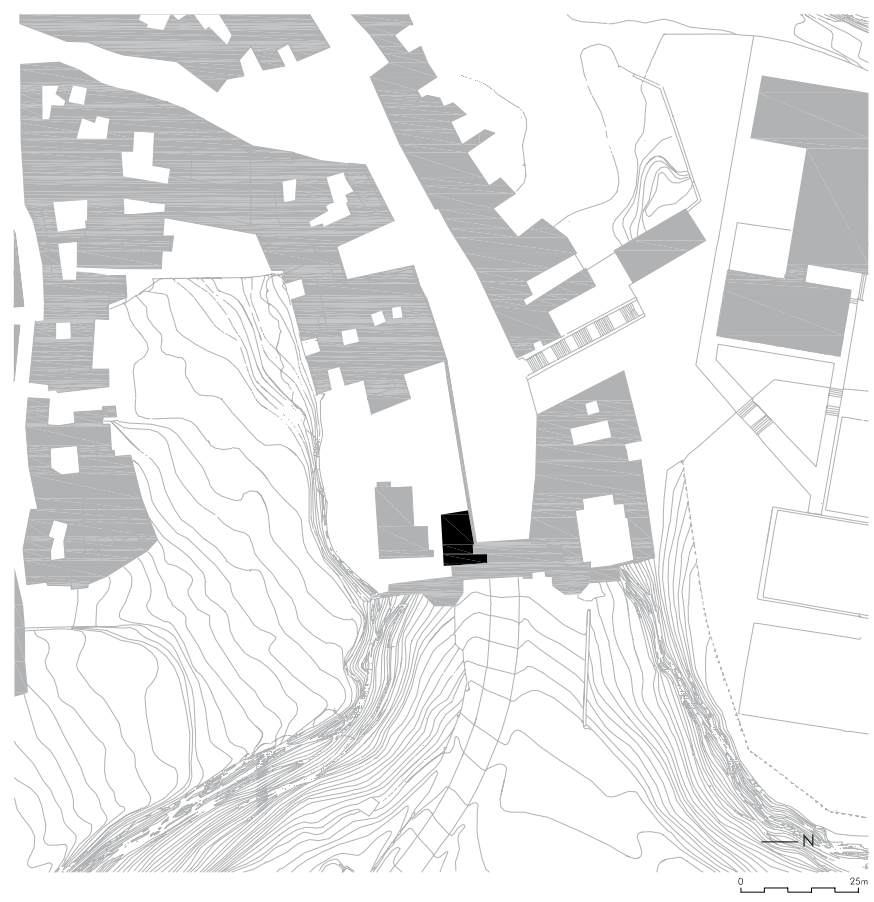

Situación. Plano: A. Tejedor, M. Linares

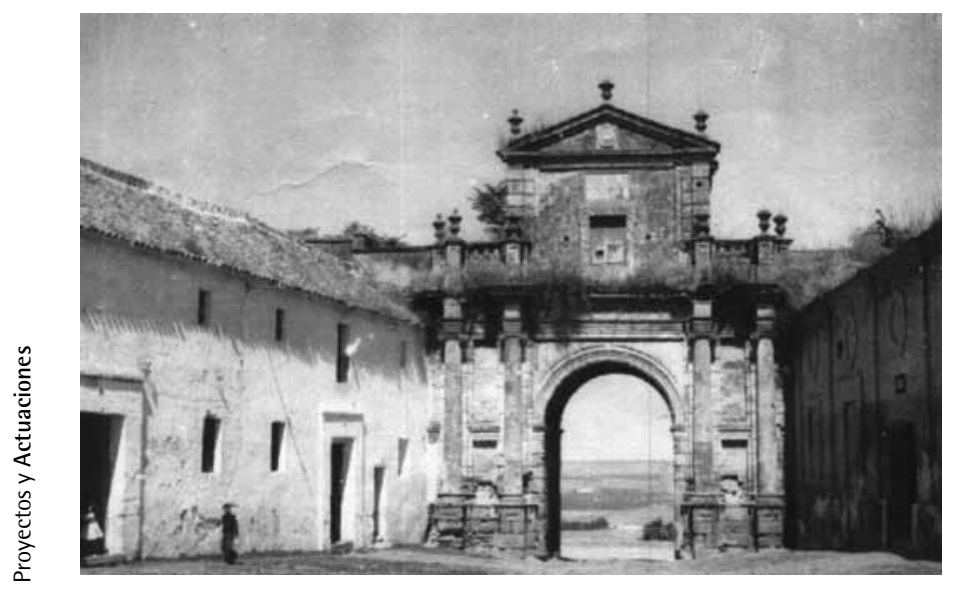

Fotografía s/f. Fuente: colección particular
Estuvo Carmona enteramente murada con fuerte muralla de argamasas y su primera altura de sillar. Tuvo 4 puertas, una a oriente, llamada de Córdoba, la que está reedificada del año 1608, y según parece, no en su antigua formación

El Curioso Carmonense. 1787

\section{CONTRA LA INTERPRETACIÓN}

En un memorable artículo de 1964, Susan Sontag construye en apenas quince páginas una demoledora visión de los excesos de la hermenéutica y una defensa argumentada y apasionada de la necesidad de recuperar la experiencia sensorial en nuestra relación con el mundo en general y con el arte en particular. En las páginas finales dice Sontag: "La nuestra es una cultura basada en el exceso, en la superproducción; el resultado es la constante declinación de la agudeza de nuestra experiencia sensorial. Todas las condiciones de la vida moderna -su abundancia material, su exagerado abigarramiento- se conjugan para embotar nuestras facultades sensoriales... Y la misión del crítico debe plantearse precisamente a la luz del condicionamiento de nuestros sentidos, de nuestras capacidades... Nuestra misión no consiste en percibir en una obra de arte la mayor cantidad posible de contenido, y menos aún en exprimir de la obra de arte un contenido mayor que el ya existente. Nuestra misión consiste en reducir el contenido de modo que podamos ver en detalle el objeto". Y termina con un aforismo definitivo que es una interpelación ética y estética: "En lugar de una hermenéutica, necesitamos una erótica del arte" (SONTAG, 1996: 38-39).

A lo largo de estos años de trabajo compartido con tantos especialistas en la restauración y la presentación del patrimonio arquitectónico hemos alimentando una inquietud: si no estamos ya decididamente instalados en un exceso tan preocupante como el que señalaba Sontag hace más de cuatro décadas a propósito del arte. Entregados a la globalización, a la venta del producto cultural, los discursos patrimoniales parecen multiplicarse hasta resultar ininteligibles, se abusa de las tecnologías de la información como si fueran una garantía de éxito popular $y$, entretanto, hemos perdido el simple y directo disfrute de la obra como tal, corroborando la idea de que "la interpretación da por supuesta la experiencia sensorial de la obra de arte, y toma a ésta como punto de partida".

Esta posición "contra la interpretación" resulta interesante para nosotros como arquitectos especialistas en patrimonio histórico. Desde luego, no somos críticos en el sentido que señala Sontag, ya que somos agentes activos, actores necesarios en la búsqueda de sentido que supone toda intervención sobre los restos del pasado. Sin embargo compartimos esta necesidad de incidir hoy más que nunca en el valor de la experiencia per se de la visita cultural. Al menos, para contraponer al exceso de interpretación una aproximación directa a la obra real, a su materialidad y a su presencia corpórea en el paisaje o en el ambiente. Frente a la sobreabundancia de discursos interpretativos, el silencio se revela como el auténtico idioma de los monumentos y la intervención sutil como la celebración del silencio. 


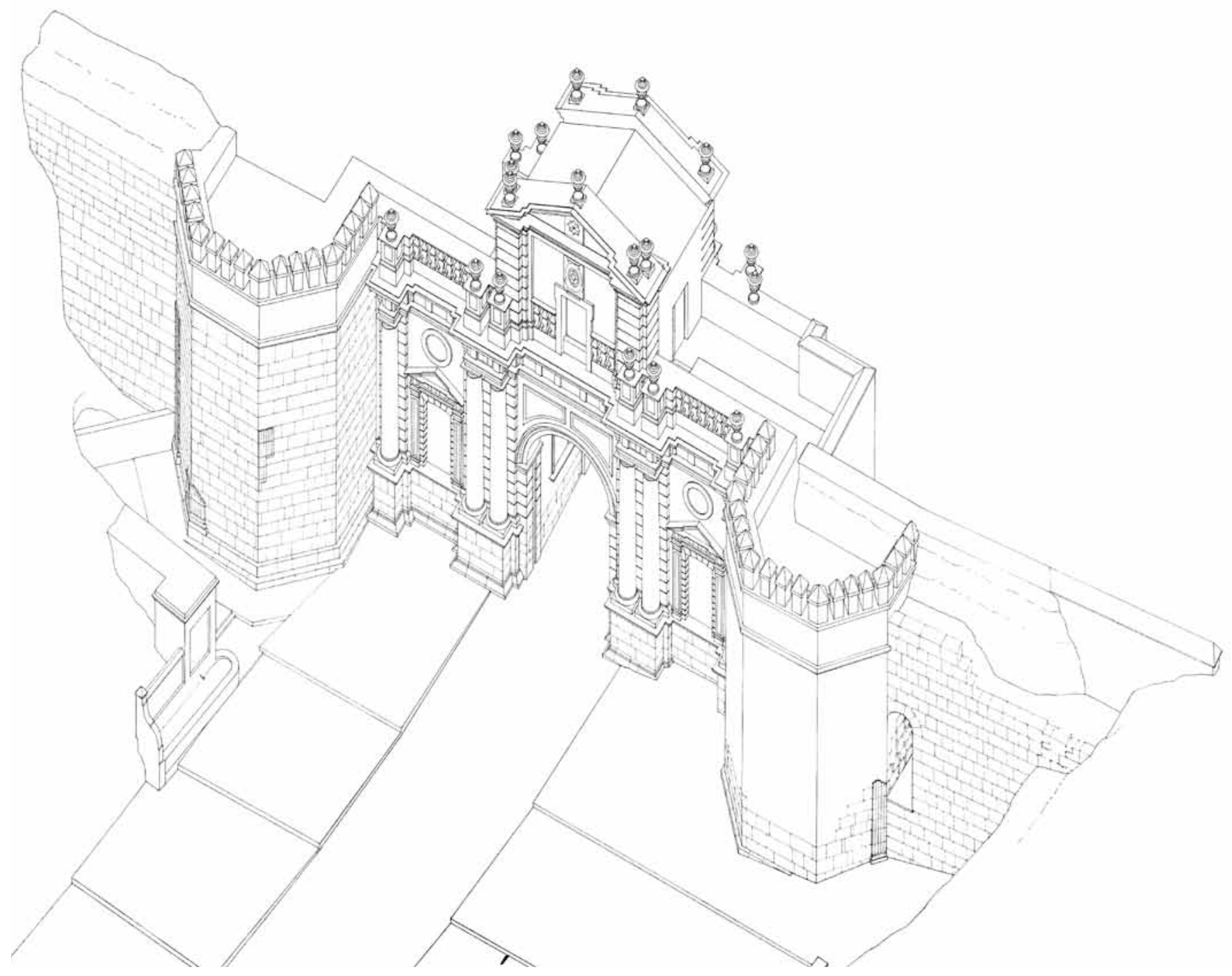

Axonométrica. Plano: A. Tejedor, M. Linares

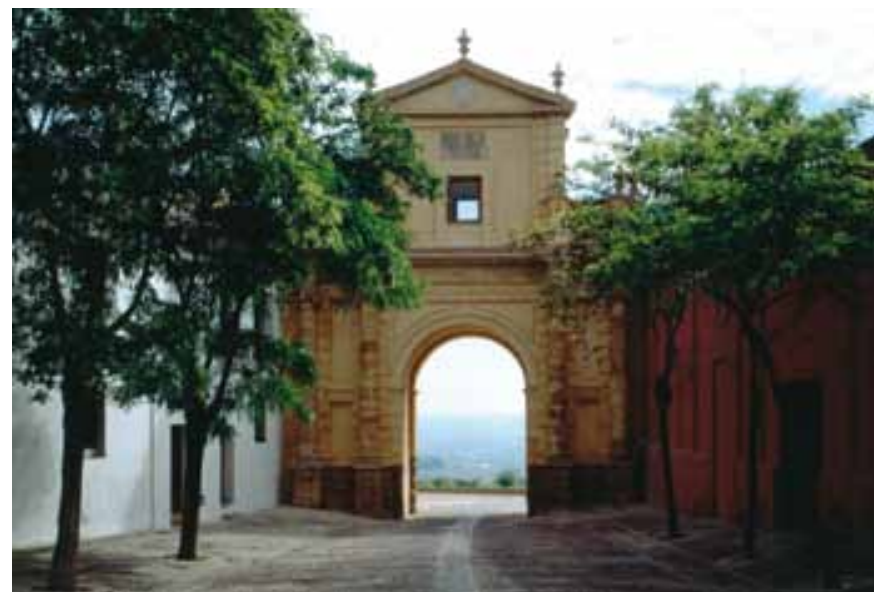

Puerta de Córdoba de Carmona. Fachada occidental. Foto: Fernando Alda

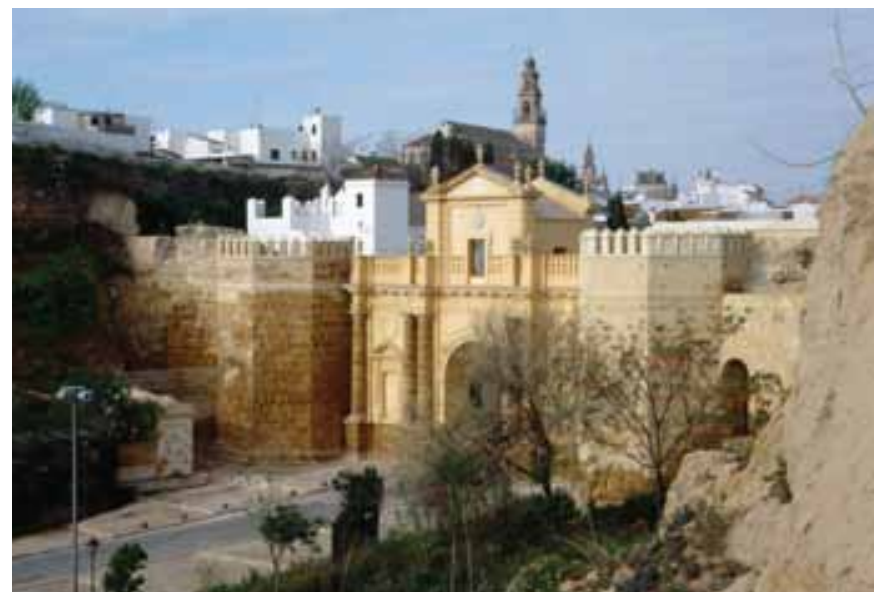

La Puerta de Córdoba en el contexto urbano de Carmona. Foto: Fernando Alda 


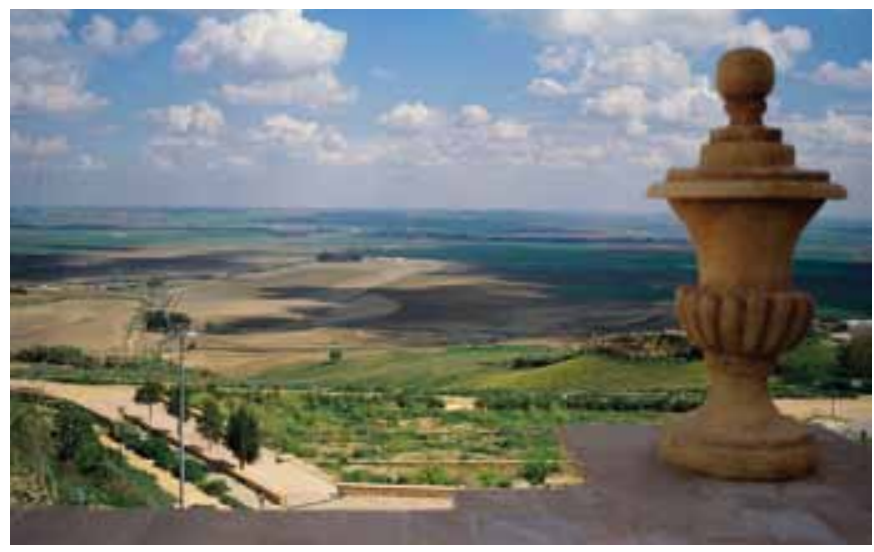

Vista de la vega del río Corbones desde la Puerta de Córdoba. Foto: Antonio Tejedor

\section{UTILIDAD DE LA AROUITECTURA PARA LA PRESENTACIÓN}

En la Puerta de Córdoba de Carmona, que habiamos restaurado entre 1995 y 2000, surgió la oportunidad de proyectar un pequeño centro de visitantes. La compra por parte del Ayuntamiento de Carmona de una pequeña superficie de la casa anexa al monumento, que era utilizada como garaje, permitió a la Consejería de Cultura de la Junta de Andalucía acometer un objetivo para nosotros no menos relevante que la propia restauración: la presentación de la Puerta de Córdoba a los visitantes. A menudo se denomina a este proceso interpretación, si bien nosotros preferimos hablar de musealización o, simplemente, de presentación, un ejercicio de comunicación que tiene en cuenta las necesidades de conservación del monumento al mismo nivel o con el mismo interés que las necesidades de fruición del público.

La interpretación en el ámbito del patrimonio arquitectónico la asociamos a fenómenos estéticos de desaparición de las cualidades previas de los objetos que se inscriben en el imaginario de una comunidad para ser sustituidas por otras cualidades de carácter devocional y afectivo. La arquitectura "interpretada" entra así con facilidad en el sistema de consumo de la industria del turismo y del ocio cultural y como consecuencia, la imagen proyectada, favorecida por el uso de las nuevas tecnologias, se convierte en algo más real que la realidad misma del bien patrimonial. Una hiperrealidad que facilita la manipulación de la imagen y convierte la interpretación en un ejercicio repleto de riesgos'.

Presentar al gran público el edificio restaurado junto a algunos pequeños bienes muebles musealizados, en un contexto adecuado, puede ser sin embargo una acción destinada a restituir unidad de conjunto a la dispersión de las cosas o sus fragmentos. Se pone en marcha así un mecanismo de identificación del espectador que siempre está latente en la relación que mantenemos con los objetos: una relación que no se agota en sí misma, ya que su fin es reconocernos en los objetos, una razón de naturaleza patrimonial. En este sentido, la presentación no sería tanto una forma de pedagogía como una actitud que se soporta en el reconocimiento sensible de las cosas².

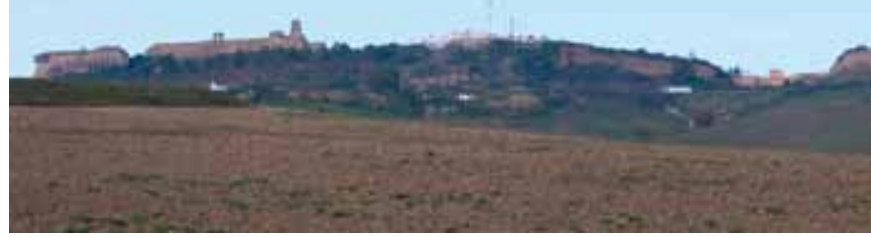

Vista general de Carmona desde la vega del río Corbones. Foto: Antonio Tejedor

En la Puerta de Córdoba se trataba de incorporar el vano peatonal sur y los restos de la fachada occidental romana, de los que se conocía su existencia gracias a la primera campaña arqueológica, al nuevo espacio visitable. Esta operación debía complementarse con otro objetivo: facilitar el acceso del visitante al ático y a los adarves de la muralla, que quedarian definitivamente desvinculados de la casa anexa que los había disfrutado en exclusiva hasta entonces. La construcción de este acceso y la exhumación de los restos se convierten así en la oportunidad deseada de disponer de un mínimo espacio necesario para la presentación de la propia Puerta de Córdoba en su complejo devenir histórico a la vez que se refuerza la oferta cultural de una ciudad que ha apostado decididamente por el turismo patrimonial.

El hecho de que el centro de visitantes esté adherido al propio monumento es una oportunidad extraordinaria para dotar a éste de un uso cultural que es la mejor garantía de una adecuada atención continuada al monumento. El uso facilita el mantenimiento y establece una pauta de conservación. La arquitectura histórica "en uso" no parece tan vulnerable. La utilitas vitrubiana da sentido a lo construido y cierra el círculo de su comprensión común y plena como paisaje y arquitectura. El uso alienta la feliz alianza de lo necesario y lo posible con lo que tiene sentido y es, quizá, el camino más corto para conseguir la identificación del ciudadano con el edificio histórico.

Son muchas las condiciones que determinan el marco de la presentación: la situación del monumento en su contexto urbano o territorial, el estado de conservación del sitio, la intensidad o frecuencia de las visitas, el público al que se dirige el discurso, etcétera. Cada una de ellas requiere de un análisis detenido y una lista de alternativas que se evalúan mediante modelos y cuestionarios que verifican la facilidad de recepción del mensaje por parte de los visitantes (en especial, los niños y los mayores). Ahora bien, si nos centrarnos en el marco arquitectónico que nos compete, defendemos una forma de presentación que utilice los recursos tradicionales de la arquitectura (la luz, el espacio, la memoria) por encima de los recursos tecnológicos tan en boga que implantados de forma abusiva han convertido a decenas de centros de interpretación en cajas negras idénticas, cansinamente repetitivas 


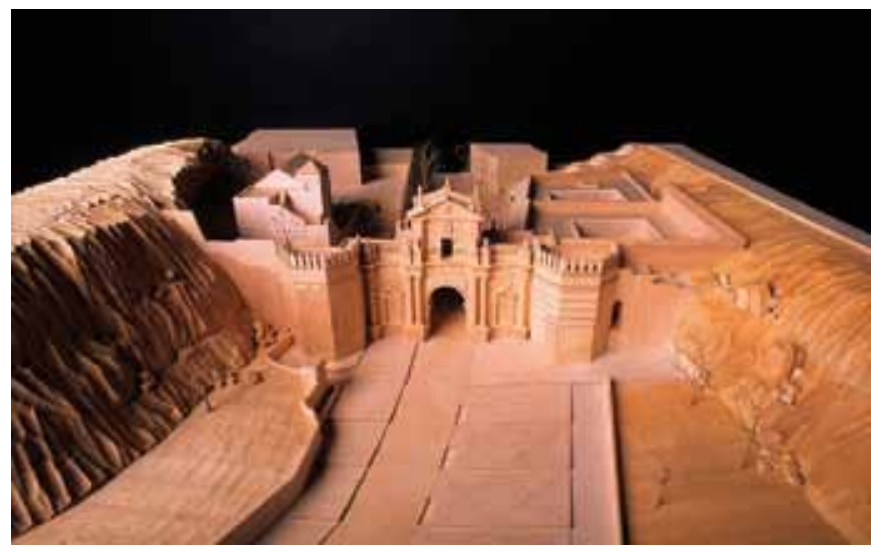

Maqueta de la Puerta de Córdoba. Foto: Eugenio Fernández Ruiz, IAPH

en la vacuidad de sus escenografias, incapaces de utilizar la luz natural y destinadas a asombrar a sus ocasionales usuarios con artefactos de luz y sonido que al poco tiempo quedan obsoletos.

\section{BREVE CRÓNICA DE UN PROYECTO}

Localizada en el extremo nordeste del casco antiguo de Carmona, esta puerta del recinto amurallado de la Carmo romana fue un extraordinario artefacto arquitectónico destinado a proclamar el poder del imperio. Su impresionante ubicación en la vaguada que permitía el acceso a la ciudad desde la vega del río Corbones, por donde discurría la Vía Augusta, explica la elaborada articulación de sus fachadas y la afortunada permanencia de sus vestigios hasta la actualidad. Por este lado del territorio, caracterizado por el abrupto escarpe de alcor, Carmona nunca sobrepasó los límites de la muralla, lo que implica la permanencia de un paisaje potencialmente similar al de hace dos milenios.

Por encargo del Instituto Andaluz de Patrimonio Histórico iniciamos en mayo de 1995 un largo proceso de estudios y proyectos para la restauración de la Puerta de Córdoba de Carmona, finalizada en febrero de 2000 cuando se cumplian doscientos años de la conclusión de la reforma neoclásica del monumento por el arquitecto carmonense José de Echamorro. Las dos campañas arqueológicas realizadas en esta primera fase permitieron conocer en profundidad, por primera vez, la fisonomía del edificio. En el lado meridional, una cavidad oscura utilizada como leñera y depósito de utensilios, presentaba una bóveda de cañón de 1,70 m de luz y 5,70 $\mathrm{m}$ de profundidad. A la izquierda se abria el hueco de paso a una escalera que debió servir de acceso al cuerpo de guardia, con su magnifica bóveda rampante. Las evidencias arqueológicas alimentaban la ilusión de recuperar la especialidad de estos pasajes excavando algo más de dos metros de profundidad hasta la cota del suelo original romano. Con este impulso se puso en marcha la segunda fase de la intervención en la Puerta de Córdoba: la creación de un centro de visitantes.

Una segunda circunstancia animaba el nuevo proyecto: disponer de un acceso al ático y a las terrazas altas del monumento

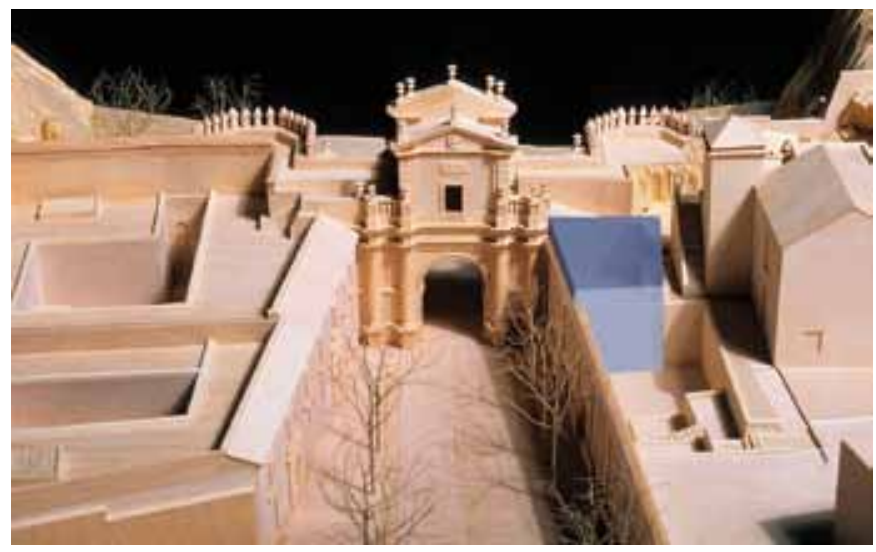

Ubicación del centro de visitantes. Foto: Eugenio Fernández Ruiz, IAPH

para desligarlo asi, definitivamente, de las casa anexa. La construcción de este acceso se entendió desde un principio como la oportunidad deseada de disponer del espacio mínimo, al nivel de la calle, necesario para la presentación de la propia Puerta de Córdoba y de los trabajos en ella realizados a lo largo de los últimos años.

El proyecto que redactamos resuelve asi dos necesidades fundamentales del inmueble para su uso público y conservación: presentar los restos restaurados del podio romano de la fachada occidental de la Puerta y construir una escalera que permita subir al ático y a las cubiertas del monumento para su mantenimiento y, especialmente, para su disfrute. El centro de visitantes se conforma, por tanto, con una nueva sala a nivel de planta baja y otra menor en el ático restaurado. La nueva sala se concibe como contenedor neutro que permite poner en valor los restos de la fachada romana. Unos escalones que sirven como pequeña grada conducen a la escalera de acero y madera que asciende por detrás de una cortina de vidrio blanco. Al atravesar ésta, un pasaje suspendido sobre el vacío interior permite divisar los restos de la puerta romana y quizás imaginar su altura original. Al salir al exterior de la caja, una escalera de piedra conduce al ático neoclásico y, un poco más arriba, a los adarves de las murallas. La cubierta de la caja está construida con vigas de madera laminada y chapa de cobre. Cuenta con dos lucernarios que iluminan cenitalmente los dos extremos de la sala en correspondencia con la fachada recuperada, por un lado, y con la nueva escalera, por el lado opuesto.

La obra permitió rescatar una parte fundamental del edificio romano original hasta su cota de pavimento original. La exhumación del podio de la fachada interior y de las galerías meridionales de la Puerta se realizó con el seguimiento de los arqueólogos Reyes 0jeda y Marco A. Gavira, quienes realizaron un registro exhaustivo de los paramentos (lienzo sur de la fachada occidental y pasaje del vano lateral sur) y los restos de enlucidos romanos (estos paramentos de piedra que iban a ser restaurados se protegieron con paneles de madera para evitar su deterioro durante toda la ejecución de la obra nueva). Los resultados de los trabajos tuvieron su expresión planimétrica, fotográfica y documental en la memoria de la campaña 


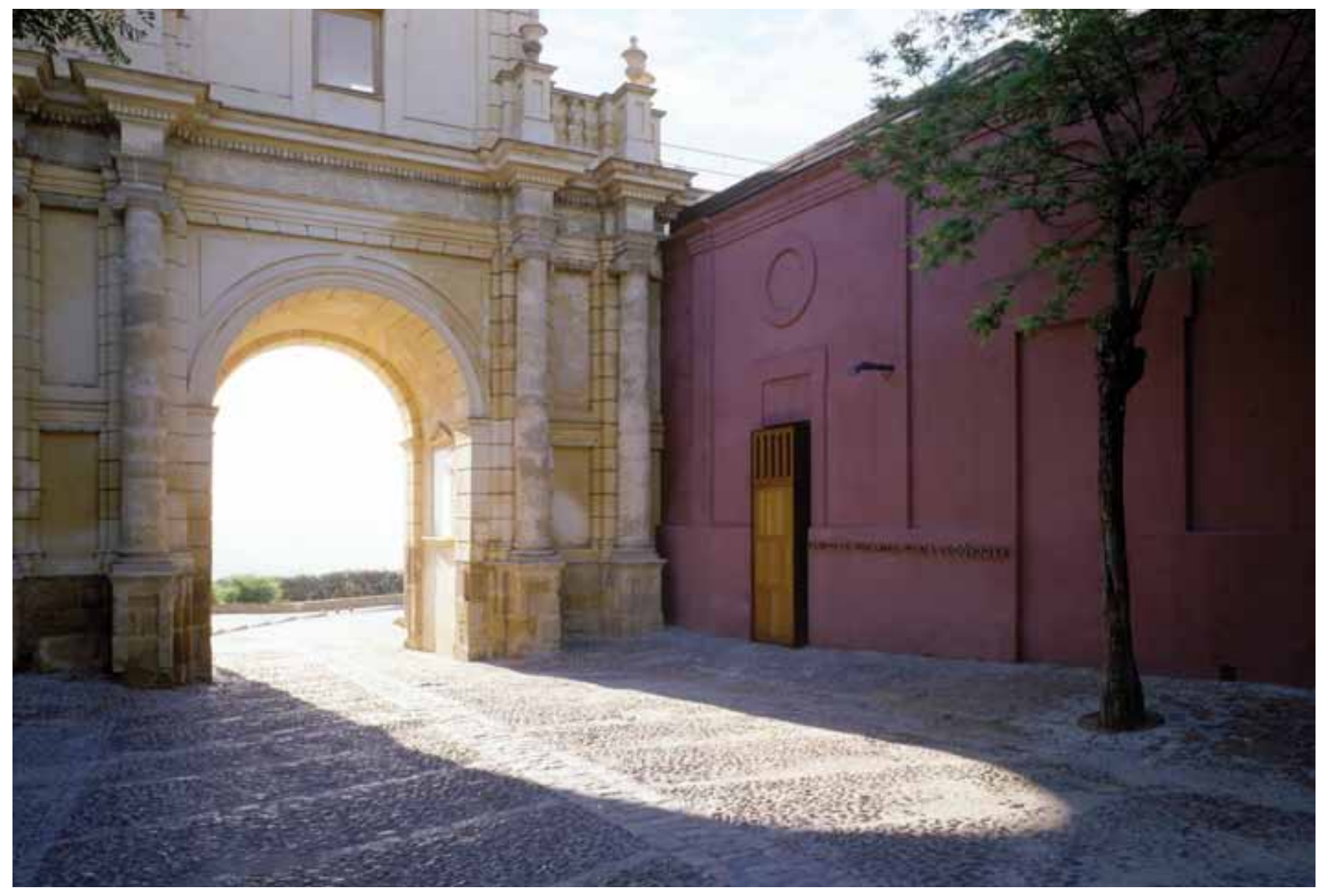

La Puerta de Córdoba desde la calle Dolores Quintanilla. Foto: Fernando Alda

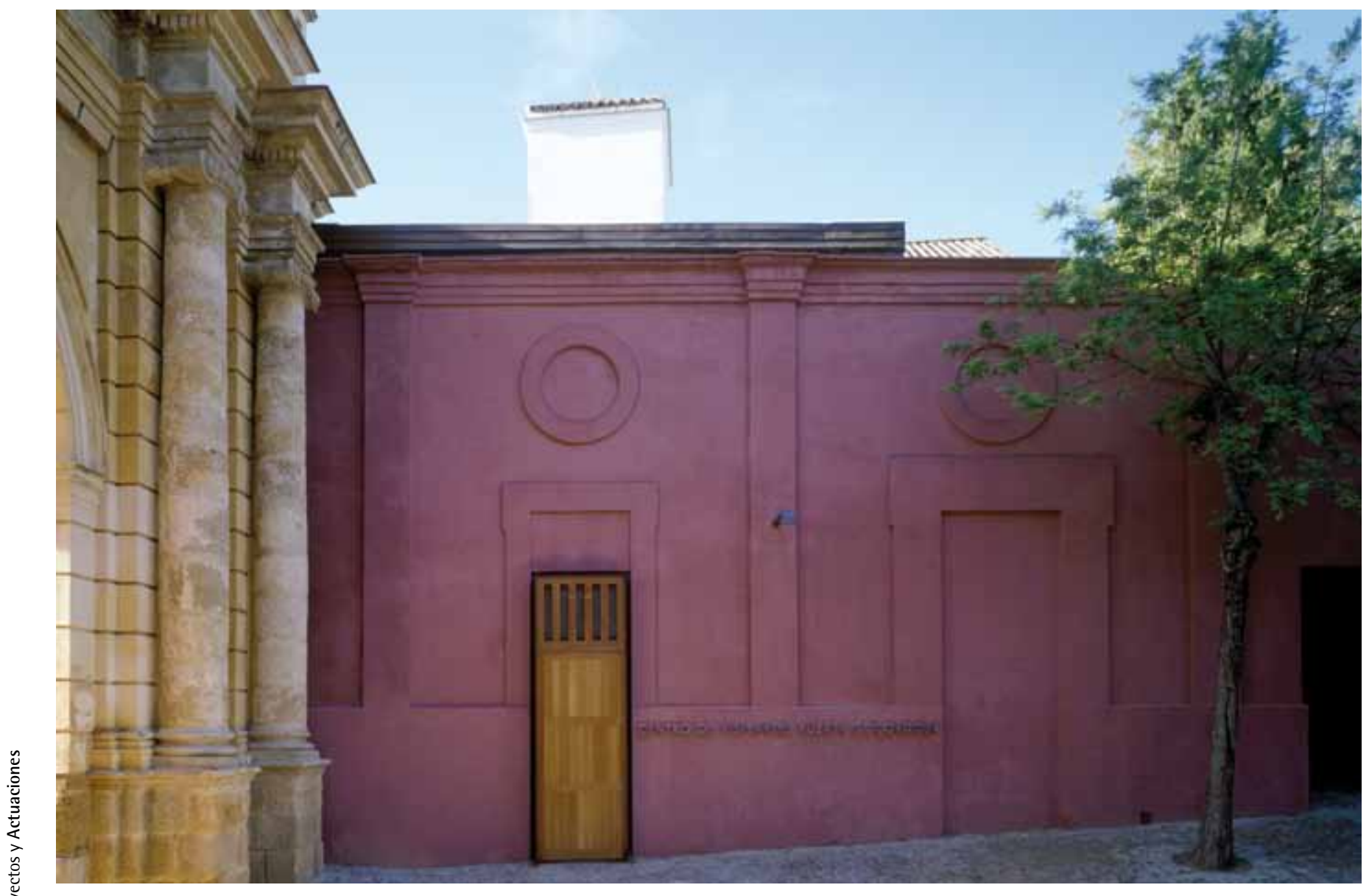

Fachada de José de Echamorro y acceso al centro de visitantes. Foto: Fernando Alda 


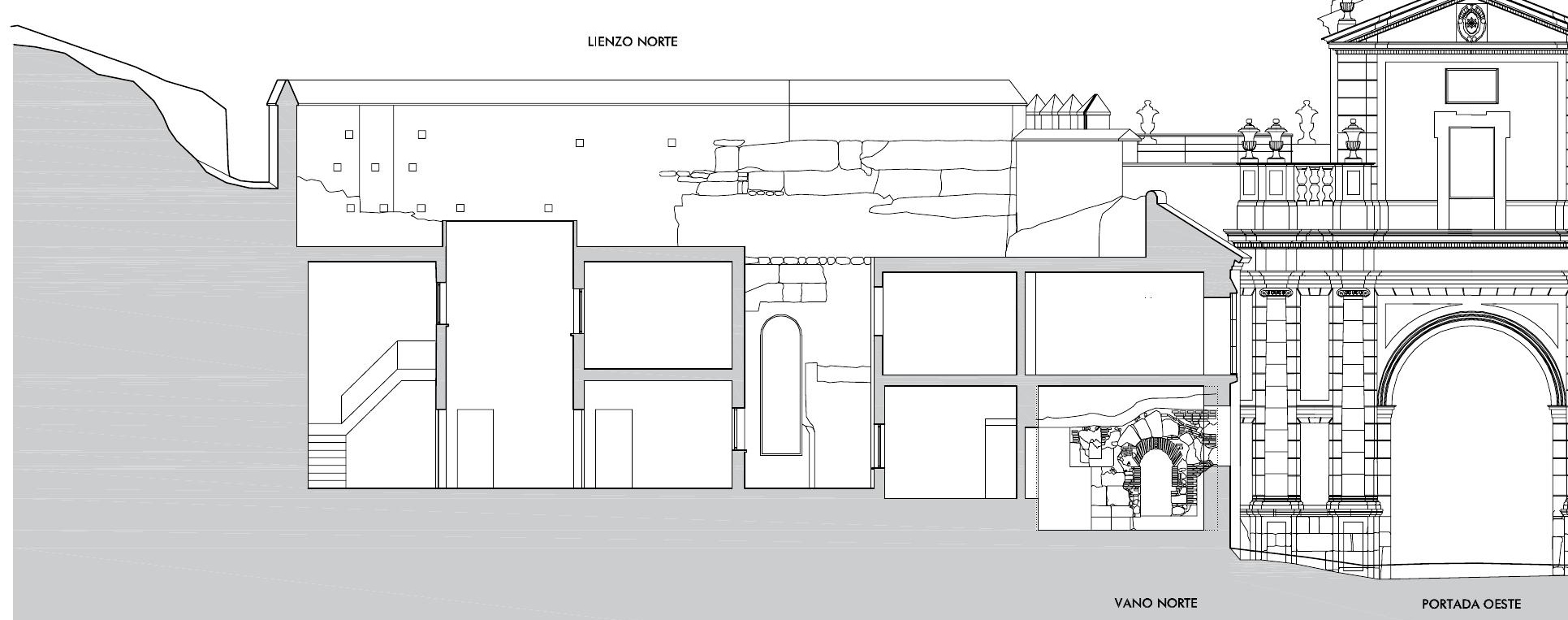

SECCIÓN ESTE

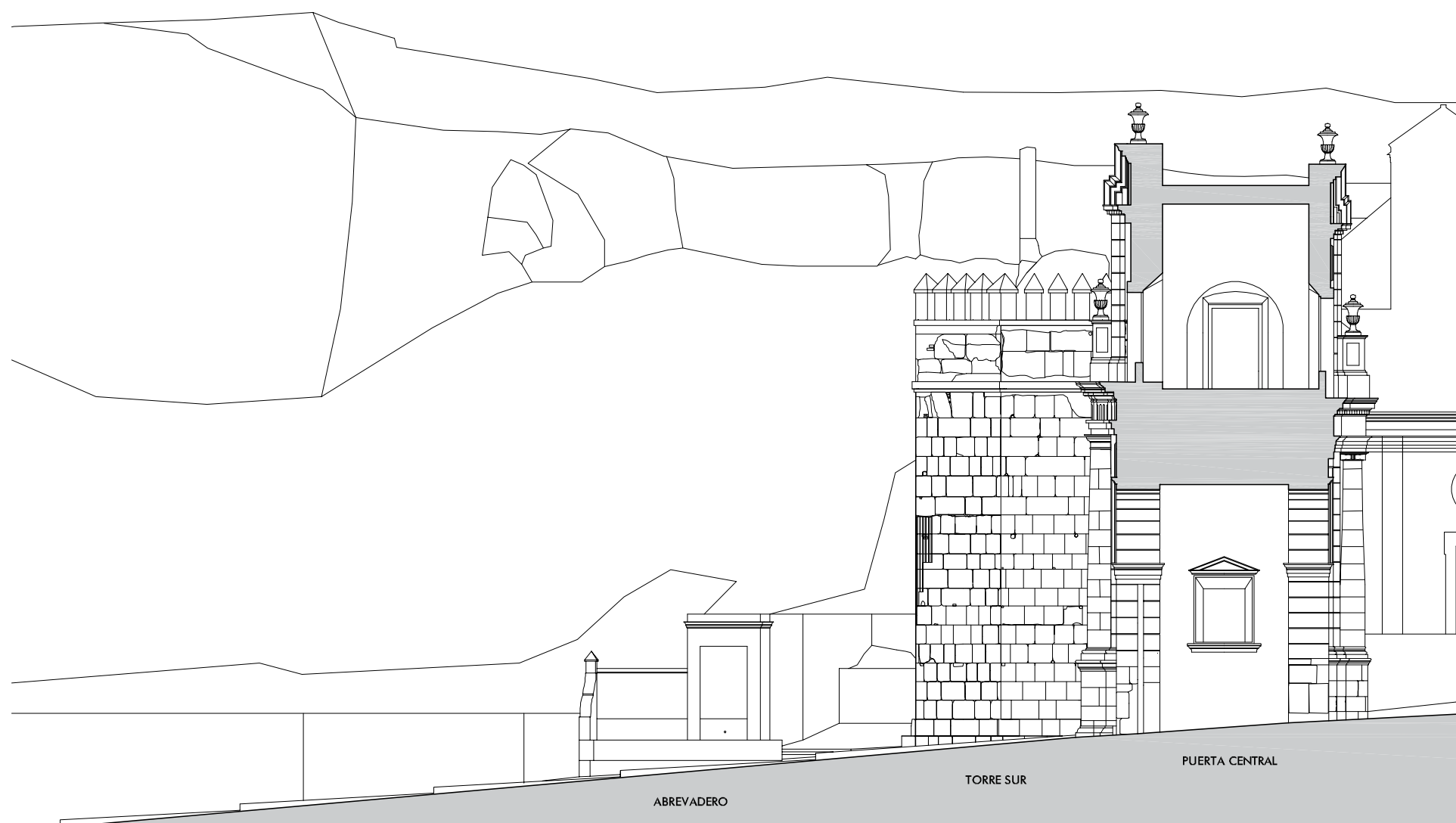




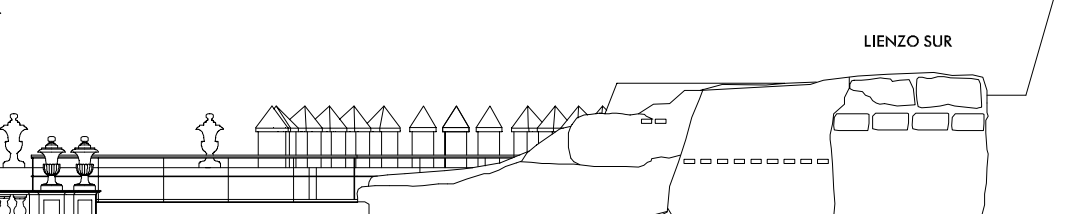
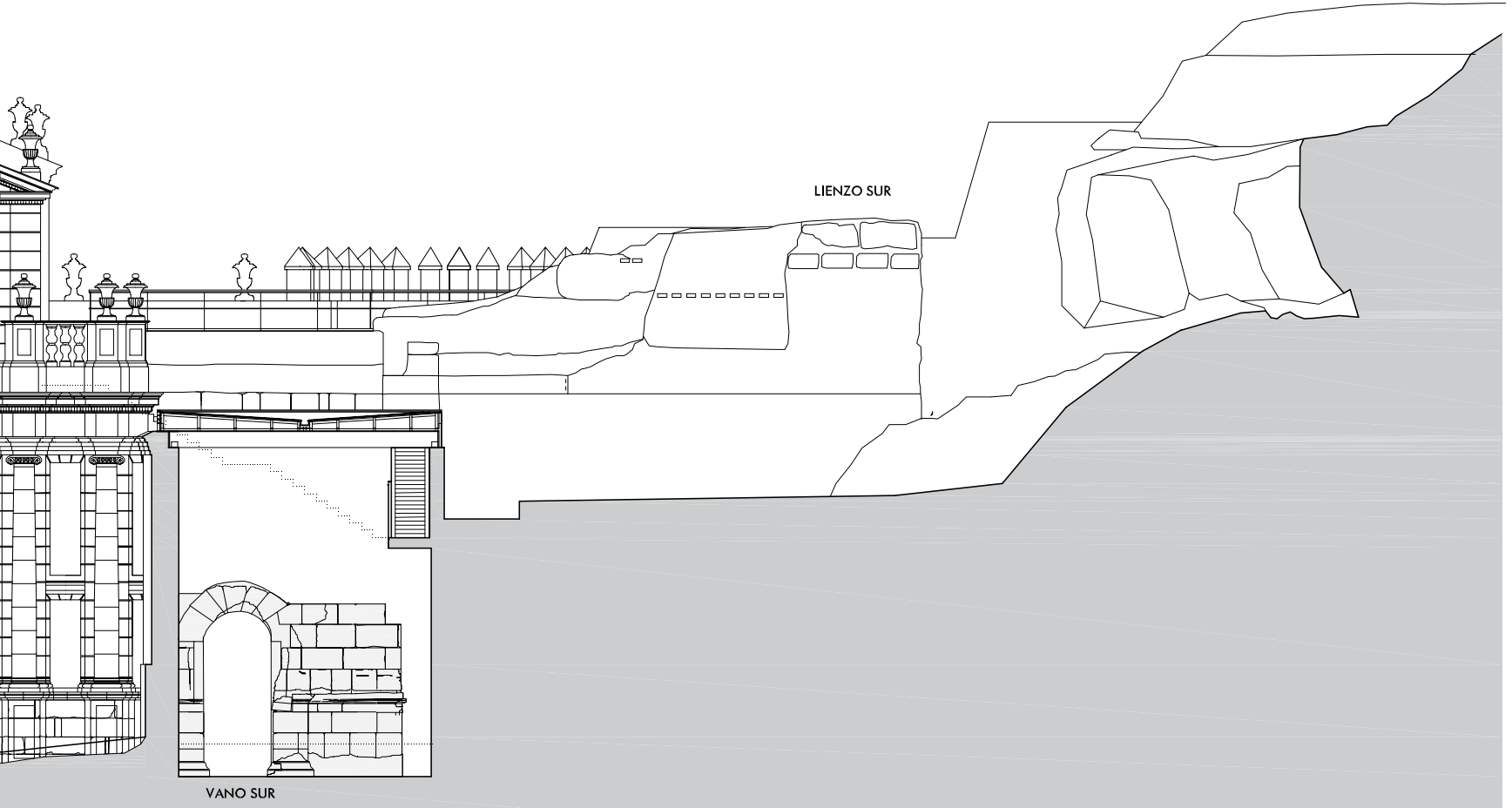


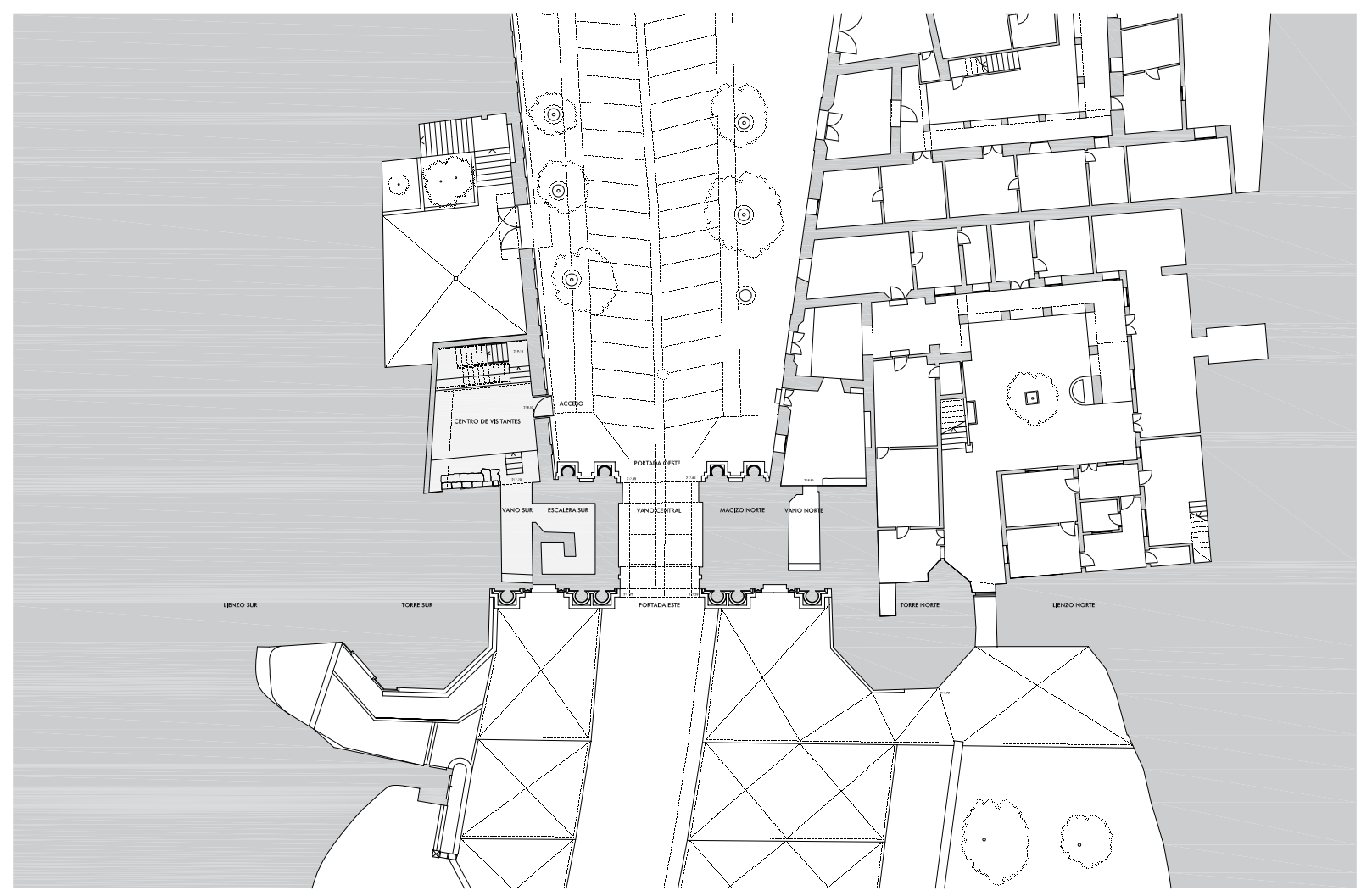

Planta general. Plano: A. Tejedor, M. Linares
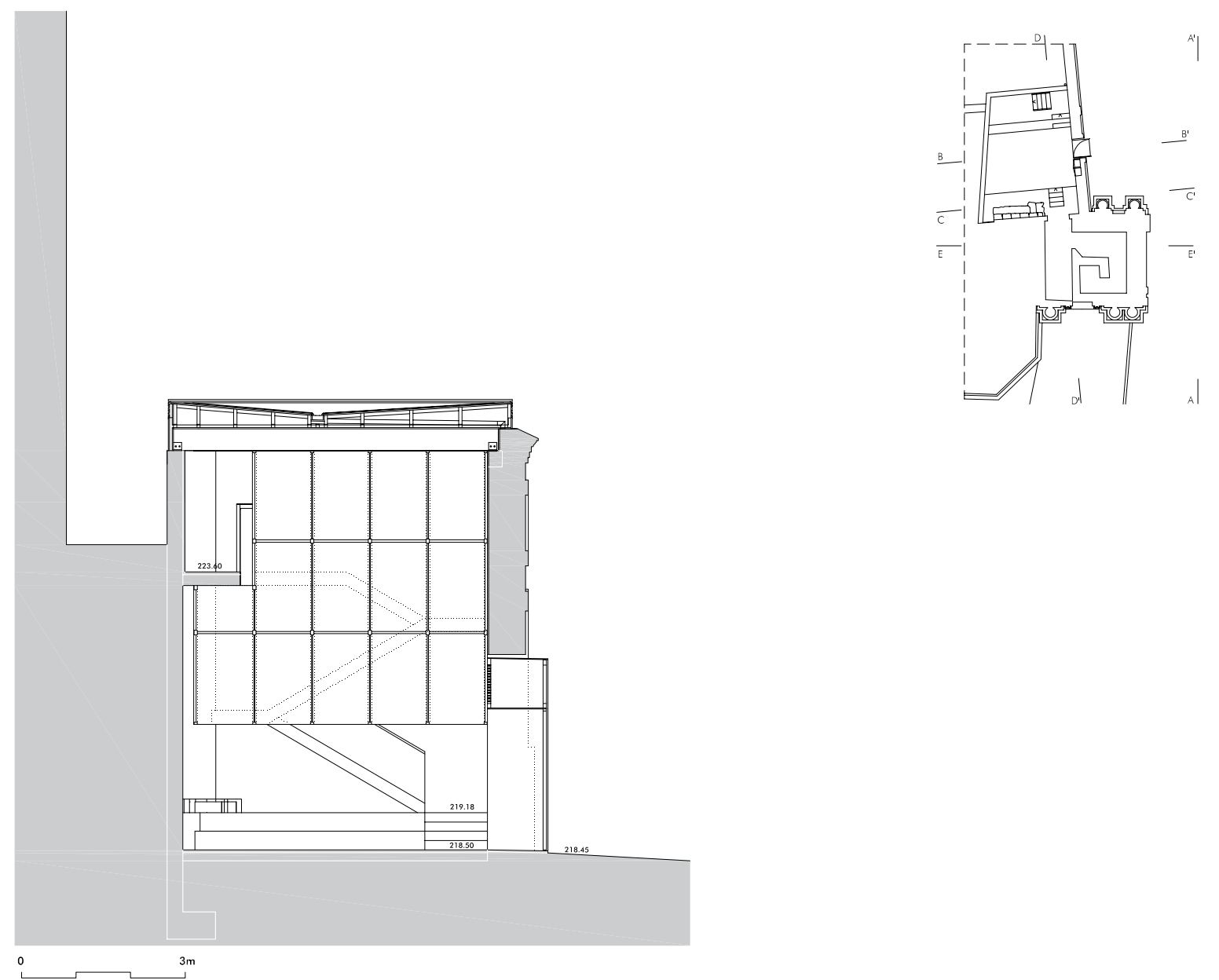


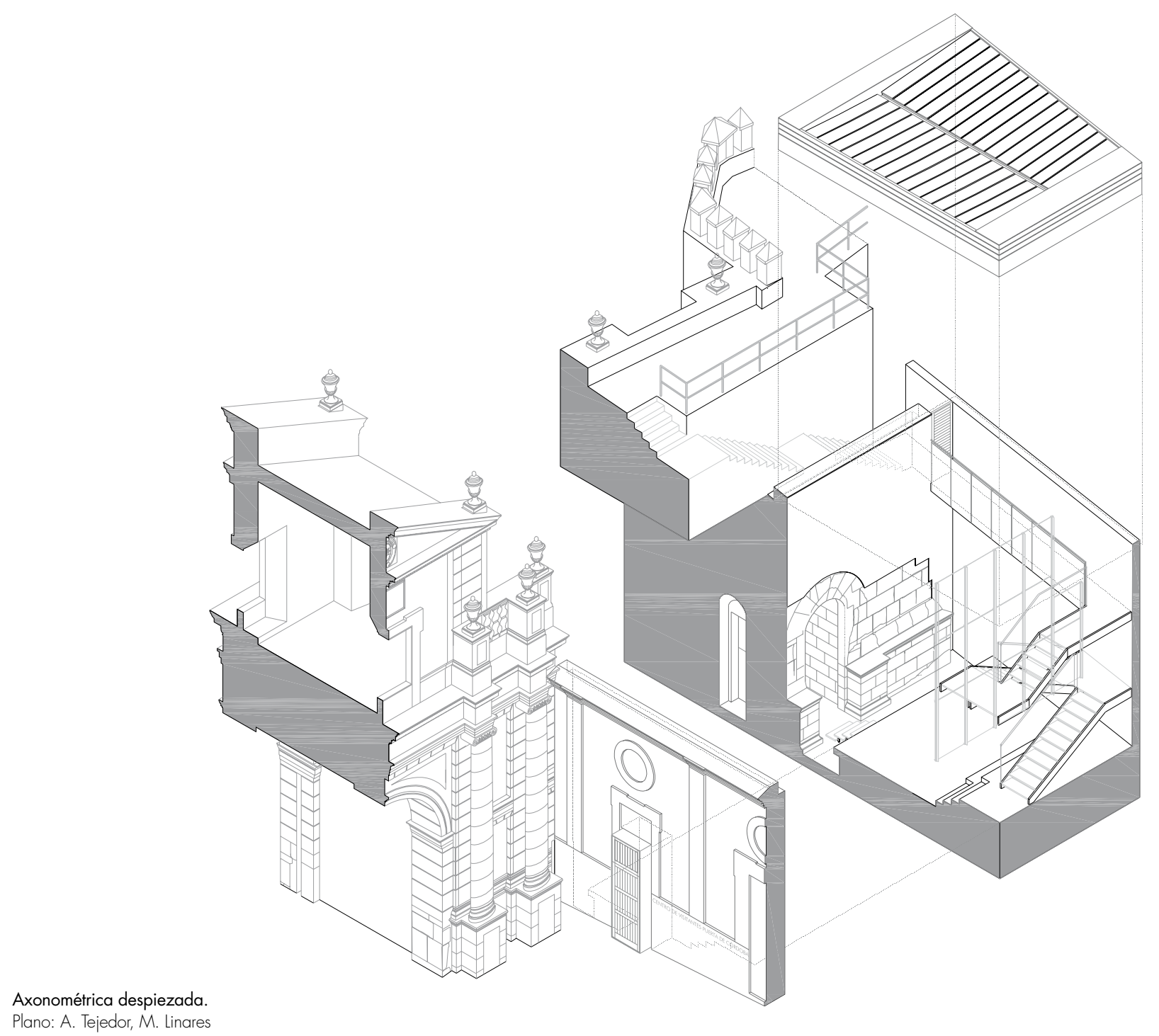

Plano: A. Tejedor, M. Linares

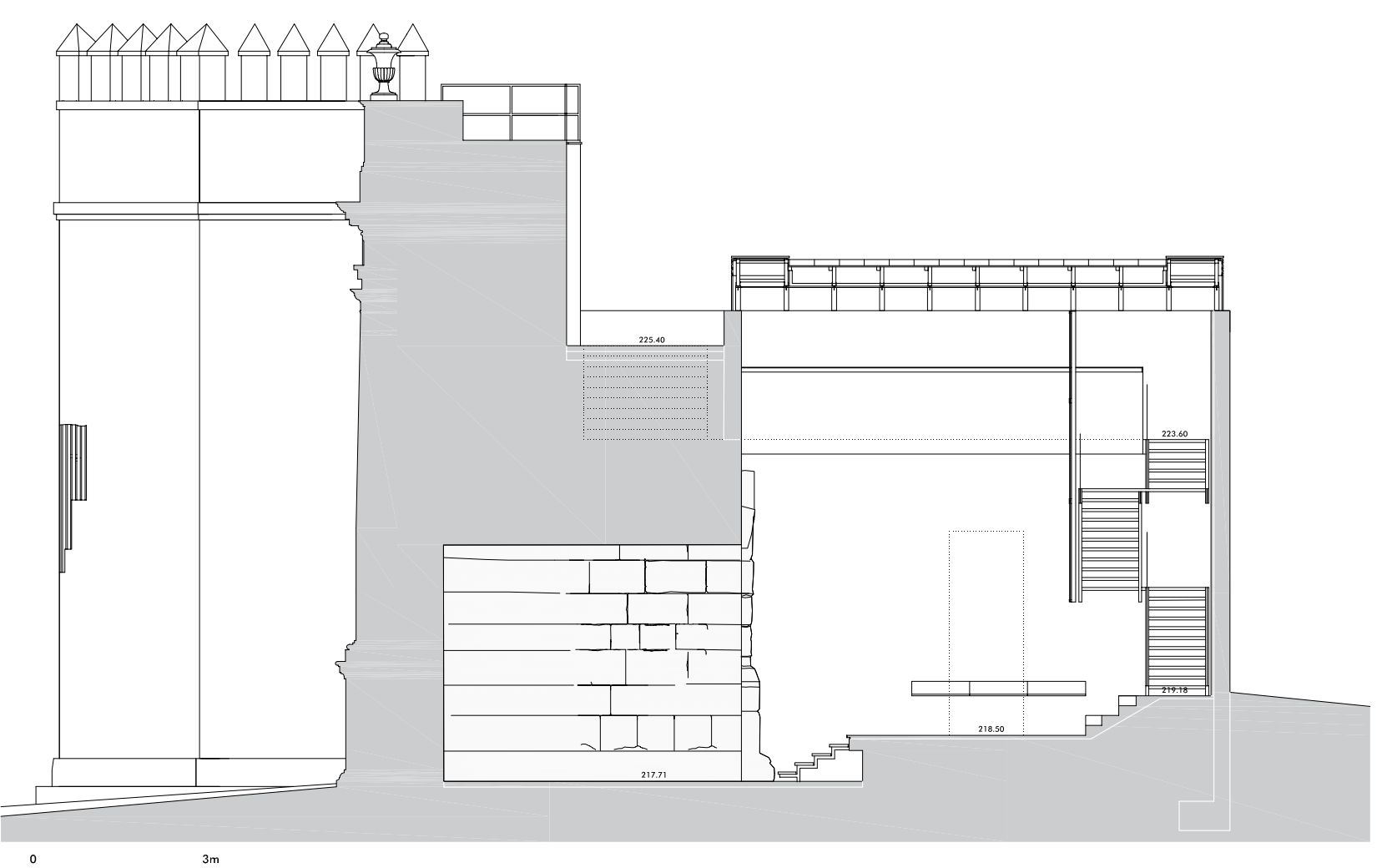

Sección DD’. Plano: A. Tejedor, M. Linares 


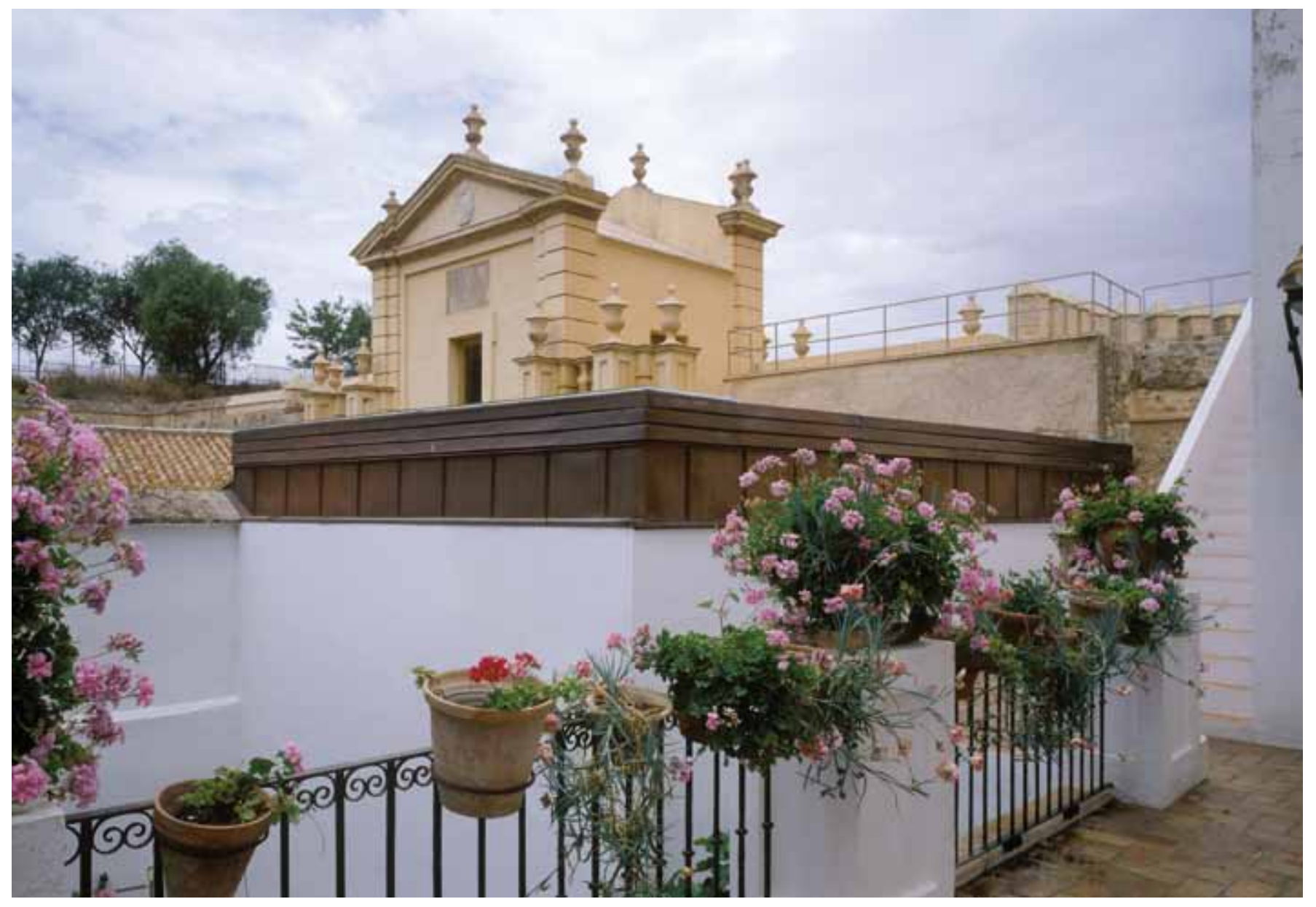

Vista del centro de visitantes desde la casa contigua. Foto: Fernando Alda

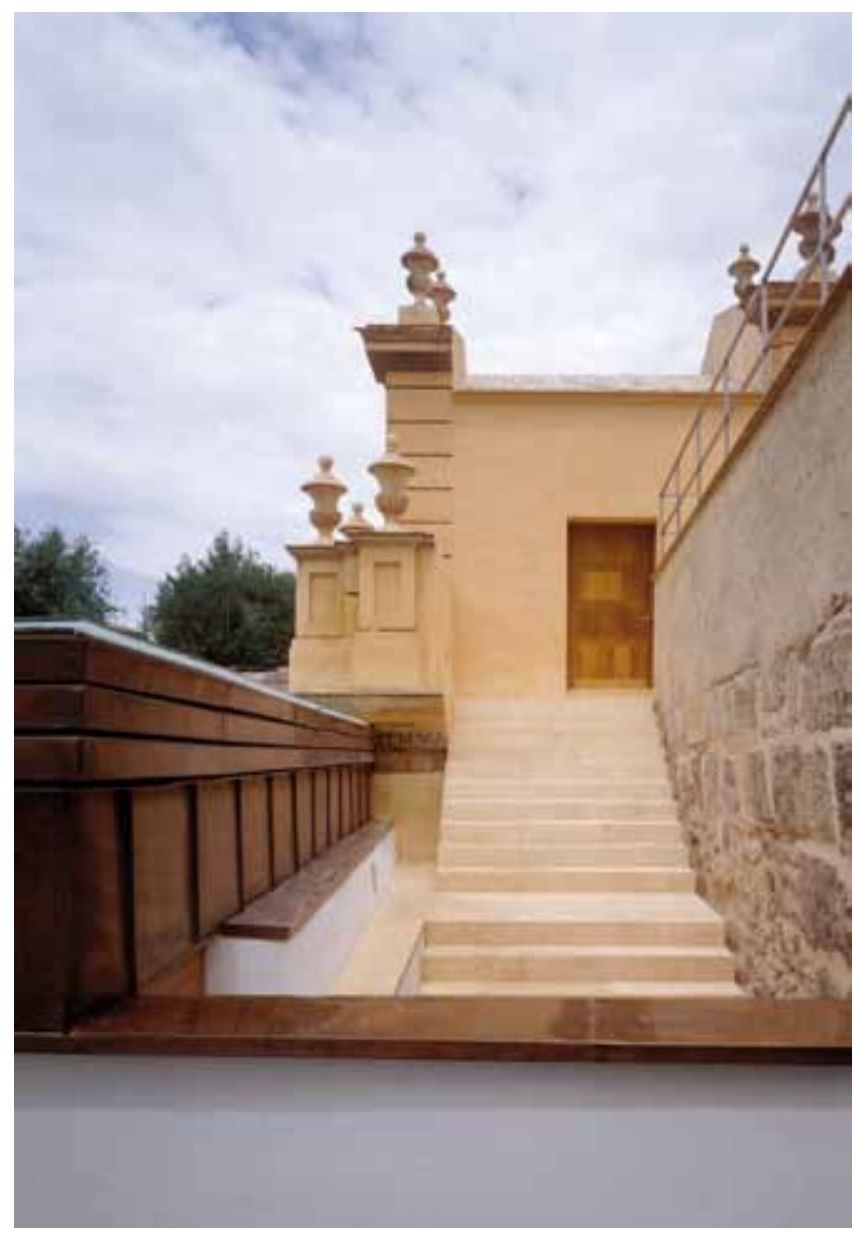

El proyecto resuelve dos necesidades fundamentales del inmueble para su uso público y conservación: presentar los restos restaurados del podio romano de la fachada occidental de la Puerta y construir una escalera que permita subir al ático y a las cubiertas del monumento para su mantenimiento y disfrute 

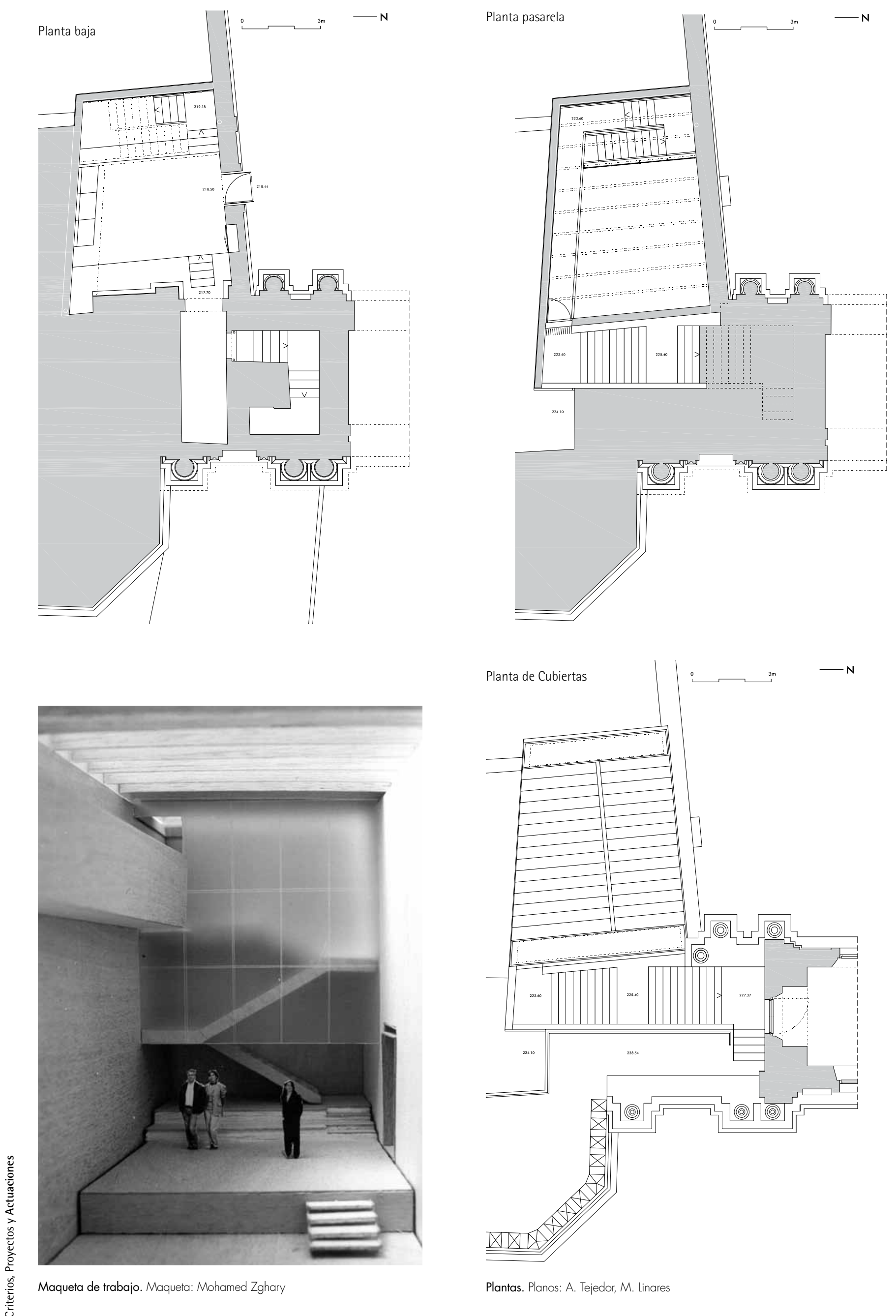

Plantas. Planos: A. Tejedor, M. Linares 
y la base de datos correspondiente de las unidades estratigráficas. El seguimiento arqueológico ${ }^{3}$ se extendió a todos los movimientos de tierras necesarios para el rebaje del nivel del suelo de la sala de planta baja y la realización de la cimentación de los nuevos muros de la caja, que se realizó por bataches en contacto con el muro de contención de la casa aledaña.

A la exhumación total de la fachada occidental de la Puerta Sur se sumaron algunos hallazgos interesantes como: la ubicación de atarjeas de época romana, islámica y moderna; la amortización de una pila de agua de opus signinum de dimensiones imprecisas; la localización de los restos de un horno de origen romano en pésimo estado, y la aparición de un tesorillo de monedas de bronce de escaso valor acuñadas en la primera mitad del s. IV.

Para la intervención sobre los muros de sillar de la Puerta romana se siguieron la metodología y los criterios recogidos en la primera fase de restauración, publicada en las páginas de esta revista en 2000, y no nos detendremos en ellos ${ }^{4}$. Baste señalar que seguimos una pauta de mínima intervención consistente, en general, en consolidar la piedra con el perfil que tenía, rejuntando y completando las lagunas de material más profundas con morteros de cal. Sólo en algún sillar, excepcionalmente deteriorado, se procedió a introducir piedra nueva de similares cualidades que la original, para recomponer la jamba izquierda de la Puerta Sur.

\section{DESVELAR}

En el artículo de la revista $P H 33$, de diciembre 2000, presentamos una propuesta de intervención, a modo de tercera fase, que diez años después no ha podido ser realizada. Nos referimos a la restauración del entorno próximo de la Puerta de Córdoba por el lado extramuros, sobre la que ya adelantamos entonces que sus objetivos "pueden considerarse, si cabe, más ambiciosos... dadas las escasas ocasiones en que, en nuestro ámbito geográfico, la restauración de los monumentos ha venido seguida de la restauración del paisaje en el que se insertan, con lo que ello significa de ruptura de inercias y viejos prejuicios". A la segunda fase debía seguir el proyecto de recuperación paisajistica del entorno de la Puerta de Córdoba, dentro de esta visión integral de restauración que pretendemos aplicar sobre el monumento en la que el tratamiento de los espacios afectados por su cuenca visual es tan importante como la restauración del propio edificio. Una desafortunada circunstancia originada en los años setenta alentaba la pertinencia de desarrollar una tercera etapa. "Con tintes tan dramáticos como el estado de conservación en que se encontraba la Puerta en 1995, podemos referirnos a la aparición del vertedero que, en pocos años, modificó la topografía de la vaguada delantera y acabó consolidado con la obra de pavimentación acometida en los primeros años 90. Quedó así truncada cualquier posibilidad de visión lejana del monumento sin que éste se viera literalmente segado por la presencia de los escombros".
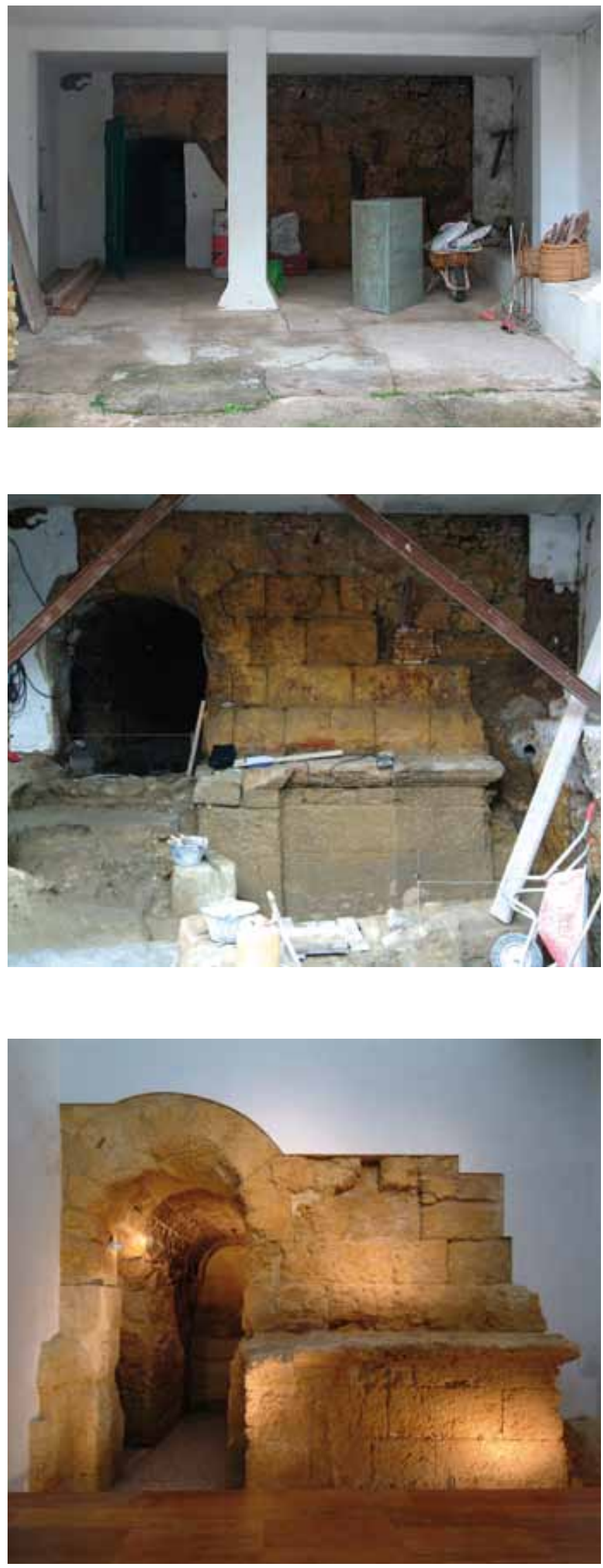

Secuencia de estados de la Puerta Sur: previo, durante la excavación y final. Fotos: Antonio Tejedor 

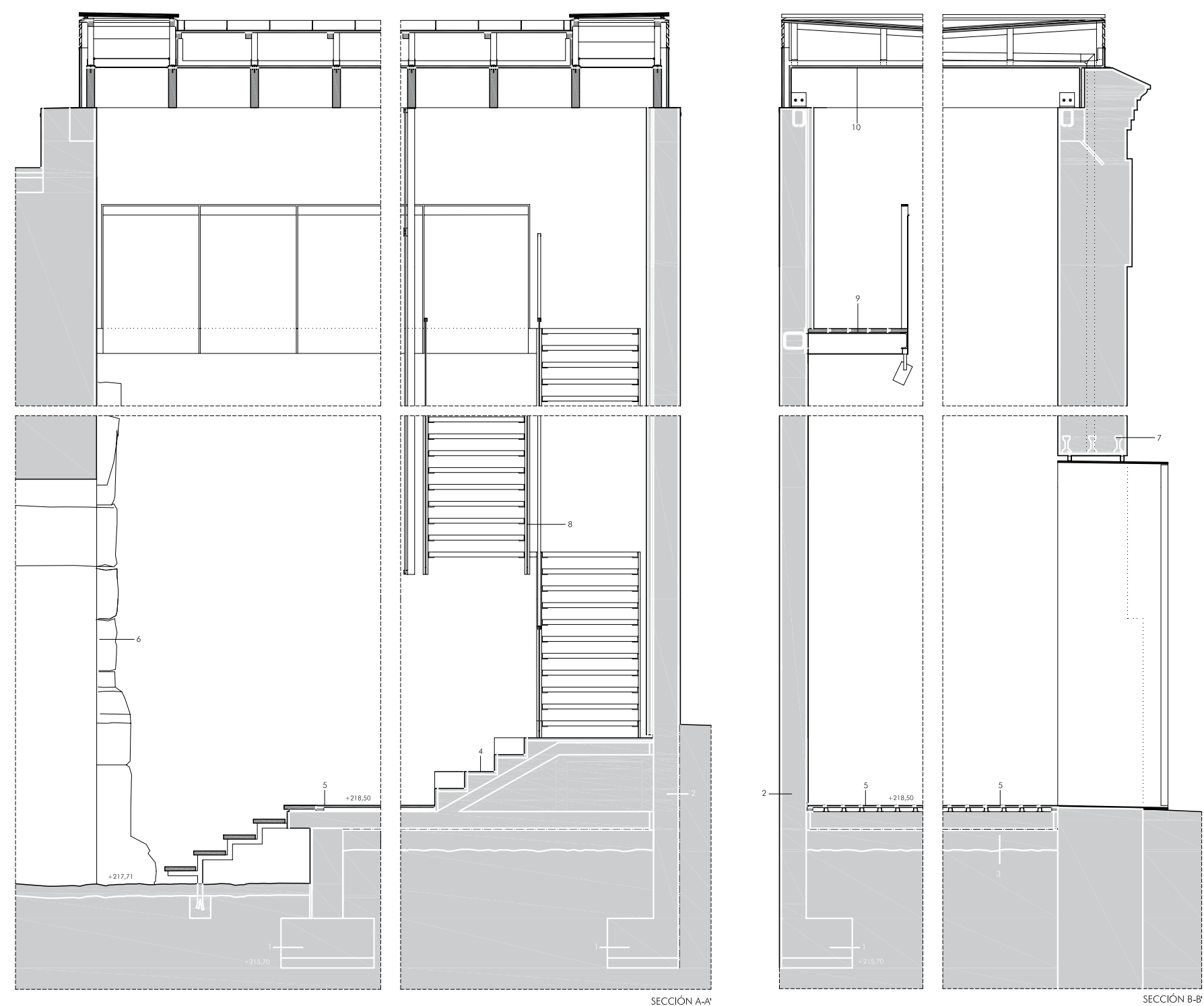

Secciones constructivas. Plano: A. Tejedor, M. Linares

\section{SECCIONES CONSTRUCTIVAS}

1. Cimentación

- Hormigón de limpieza hm-15 e. 10 cm

- Zapata corrida de hormigón armado

ha-25.

- Relleno de zahorra seleccionada y compactada al $95 \%$ proctor modificado.

\section{Muro de contención}

- Muro de hormigón armado ha-25

e. $25 \mathrm{~cm}$.

- Junta estanca de bentonita en encuentro de muro con zapata.

- Junta de poliestireno expandido en contacto con muro de la casa. e. $2 \mathrm{~cm}$.

- Terminación interior y exterior con enfoscado de mortero bastardo y revoco de cal y marmolina coloreado en masa. - Terminación interior en testero oeste y pasarela con trasdosado en cartón yeso e. $16 \mathrm{~mm}$ y aislamiento de lana de roca e. $4 \mathrm{~cm}$.
3. Formación de solera

- Solera de hormigón hm-20 con malla electrosoldada b500s.

- Film de polietileno de alta densidad sobre grava e. $20 \mathrm{~cm}$.

- Zahora seleccionada y compactada al $95 \%$ proctor modificado.

4. Formación de meseta y peldaños interiores

- Losa de hormigón armado ha-25 e. 15 $\mathrm{cm}$ sobre tabiques conejeros de citara de ladrillo perforado y rasillones de $70 \mathrm{~cm}$

- Formación de peldaños con ladrillo hueco y mortero m-40.

- Revestimiento de piedra natural travert no blanco en gran formato e. $3 \mathrm{~cm}$.

- Rodapié de perfil I100.30.2 de acero inoxidable.

- Asientos de tablas de madera de elondo machiembradas sobre rastreles de omega galvanizada cada $40 \mathrm{~cm}$.
5. Pavimento de sala

- Entarimado de madera de elondo en tablas machiembradas de $120 \times 22$ $\mathrm{mm}$, sobre rastreles de omegas galvanizadas cada $40 \mathrm{~cm}$. Y protección con barniz de poliuretano

- Remate en canto libre con tabla de elondo idem escalones.

- Rodapié idem 4.

\section{Tratamiento y restauración de} paramentos de piedra

- Limpieza, desinfección y preconsolidación de piedra.

- Rejuntado de sillares con mortero de cal y marmolina coloreado en masa. - Reparación de molduras de piedra calcarenita.

- Consolidación con éster de sílice oh. - Hidrofugación con siloxano tegosivín hl-100.

- Patinado de paramentos.

\section{Formación de dinte}

- Apertura de hueco en muro de ladrillo existente.

- Viguetas autorresistentes y ladrillo macizo

\section{Escalera interior}

- Zancas de doble platabanda de acero 250/215.20

- Peldaños de madera de blondo

340.50

- Baranda de vidrio laminado 6+6 mm

\section{Pasarela}

- Vigas ipn 160 ancladas al muro de hormigón.

- Solería de madera de blondo machihembrada.

- Baranda de acero inox 60. 15 y chapa de acero lacado blanco e. $4 \mathrm{~mm}$.

\section{Cubierta}

- Ver detalles constructivos. 

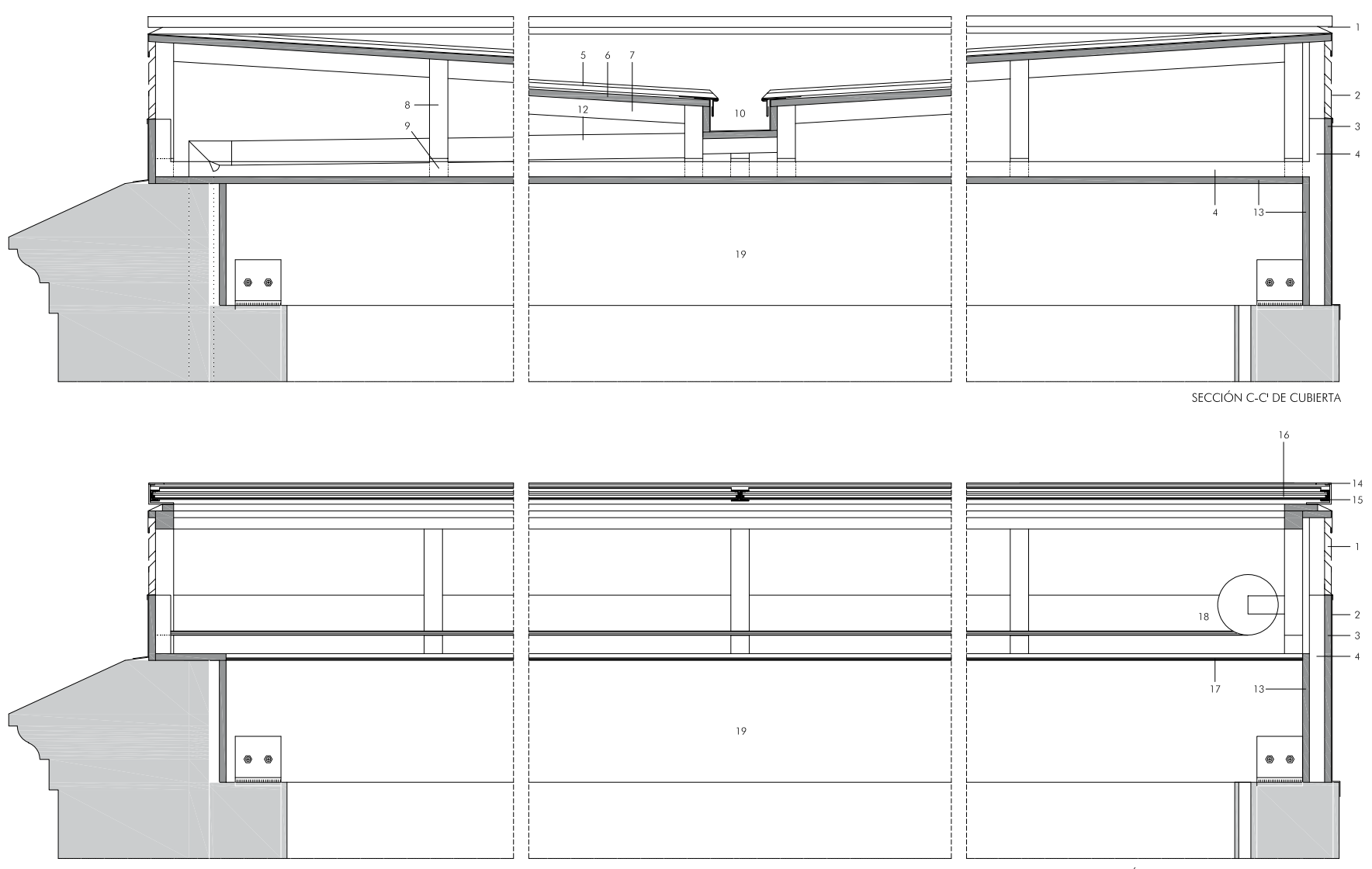

SECCIÓN B-B' DE CUBIERTA POR LUCERNARIO

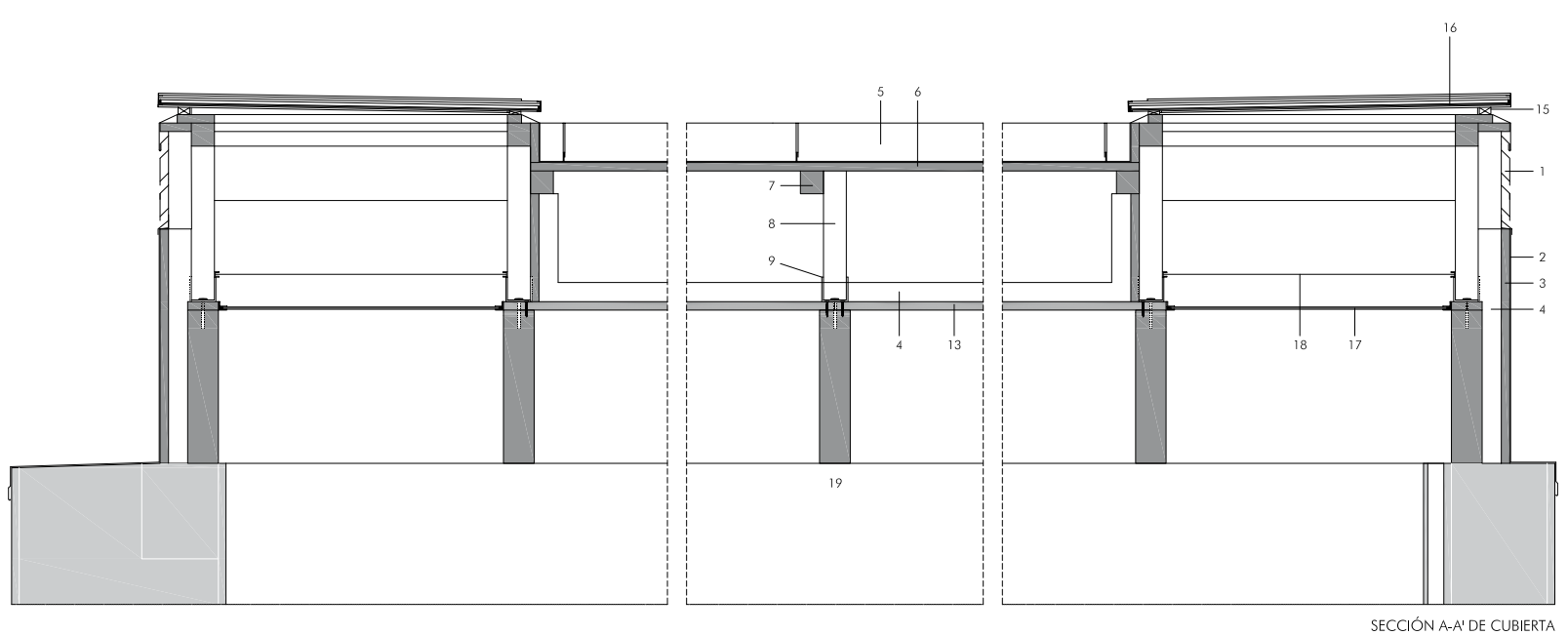

Detalles constructivos de la cubierta de madera laminada y cobre. Plano: A. Tejedor, M. Linares

\section{DETALIES CONSTRUCTIVOS}

1. Rejilla de ventilación de cobre espesor 0,70 $\mathrm{mm}$ con barrera antiinsectos.

2. Remate lateral en hojas de cobre

e. $0.60 \mathrm{~mm}$.

3. Tablero de madera de pino silvestre

e. $22 \mathrm{~mm}$.

4. Aislamiento de lana de roca e. $5 \mathrm{~cm}$

5. Hojas de cobre de $500 \mathrm{~mm}$ de anchura y $0.60 \mathrm{~mm}$ de espesor unidas con junta alzada.

6. Entarimado de madera de pino

silvestre de $100 \mathrm{~mm}$ de anchura 6 y 22

$\mathrm{mm}$ de espesor.
7. Listones de madera de pino silvestre de escuadría $60 \times 60 \mathrm{~mm}$.

8. Pies de madera de pino silvestre de escuadría $60 \times 60 \mathrm{~mm}$.

9. Perfil de chapa de acero laminado

de sección 80.70 .5 y 9 de anchura

$60 \mathrm{~mm}$ para fijación de los pies de

madera.

10. Canalón de cobre de $0.70 \mathrm{~mm}$ de espesor.

11. Codo tipo delfín en cobre de $\varnothing$ $80 \mathrm{~mm}$.
12. Tubería de cobre de $\varnothing 80 \mathrm{~mm}$ y

$0,70 \mathrm{~mm}$ de espesor.

13. Tablero de madera laminada de 22 $\mathrm{mm}$ de espesor.

14. Marco exterior de cobre e $=2 \mathrm{~mm}$ con evacuación de agua en uno de sus lados.

15. Carpintería interior de aluminio anodinado.

16. Vidrio superior laminado $(6+6 \mathrm{~mm})$ Cámara de aire $(8 \mathrm{~mm})$ y vidrio inferior laminado $(3+3 \mathrm{~mm})$
17. Vidrio laminado $(3+3 \mathrm{~mm})$ de butiral blanco con juntas entre vidrios abiertas $(15 \mathrm{~mm}$ ) y a una distancia de $1500 \mathrm{~mm}$.

18. Estor opaco motorizado sobre guías con tejido ignífugo $\mathrm{m} 1$ en hilos de fibra de vidrio recubiertos de PVC termofijados.

19. Viga de madera laminada de pino sueco $400 \times 80 \mathrm{~mm}$ con tratamiento antixilófagos y contraincendios. 


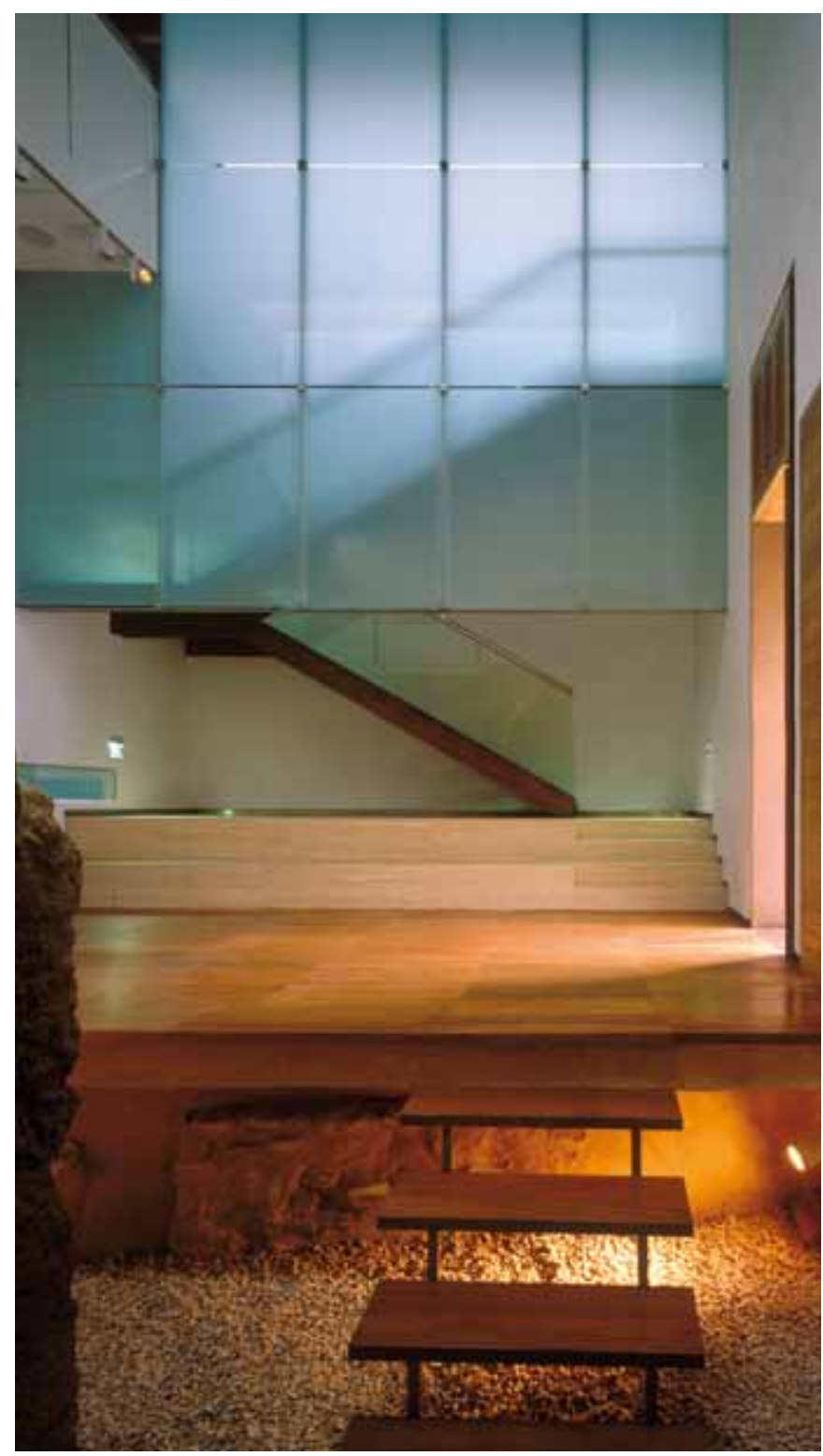

Cortina de vidrio blanco. Foto: Fernando Alda

Otras actuaciones como la consolidación de la vía Augusta que asciende por la vaguada desde época romana, cuyos restos afloran en la ladera del alcor, y la restauración del Ilamado puente de los Cinco Vanos sí fueron acometidas por el Ayuntamiento de Carmona con la ayuda del Ministerio de Cultura. Sin embargo, la eliminación del vertedero para la necesaria recuperación del perfil natural de la vaguada no se ha podido iniciar aún, ni la modificación del precario jardín delantero de inicios de los 90 ni otras iniciativas complementarias, tan importantes como las anteriores, que habiamos propuesto: la consolidación del escarpe de alcor en los tramos contiguos a los lienzos de muralla cuya erosión afecta a la conservación de las estructuras murarias, las nuevas plantaciones de arbolado y vegetación en la ladera, la nueva iluminación monumental. Actuaciones sobre el entorno que debian ir acompañadas de la eliminación de los cobertizos que jalonan el camino de llegada a la Puerta de Córdoba por el Sur, de los tendidos eléctricos que cruzan a unas decenas de

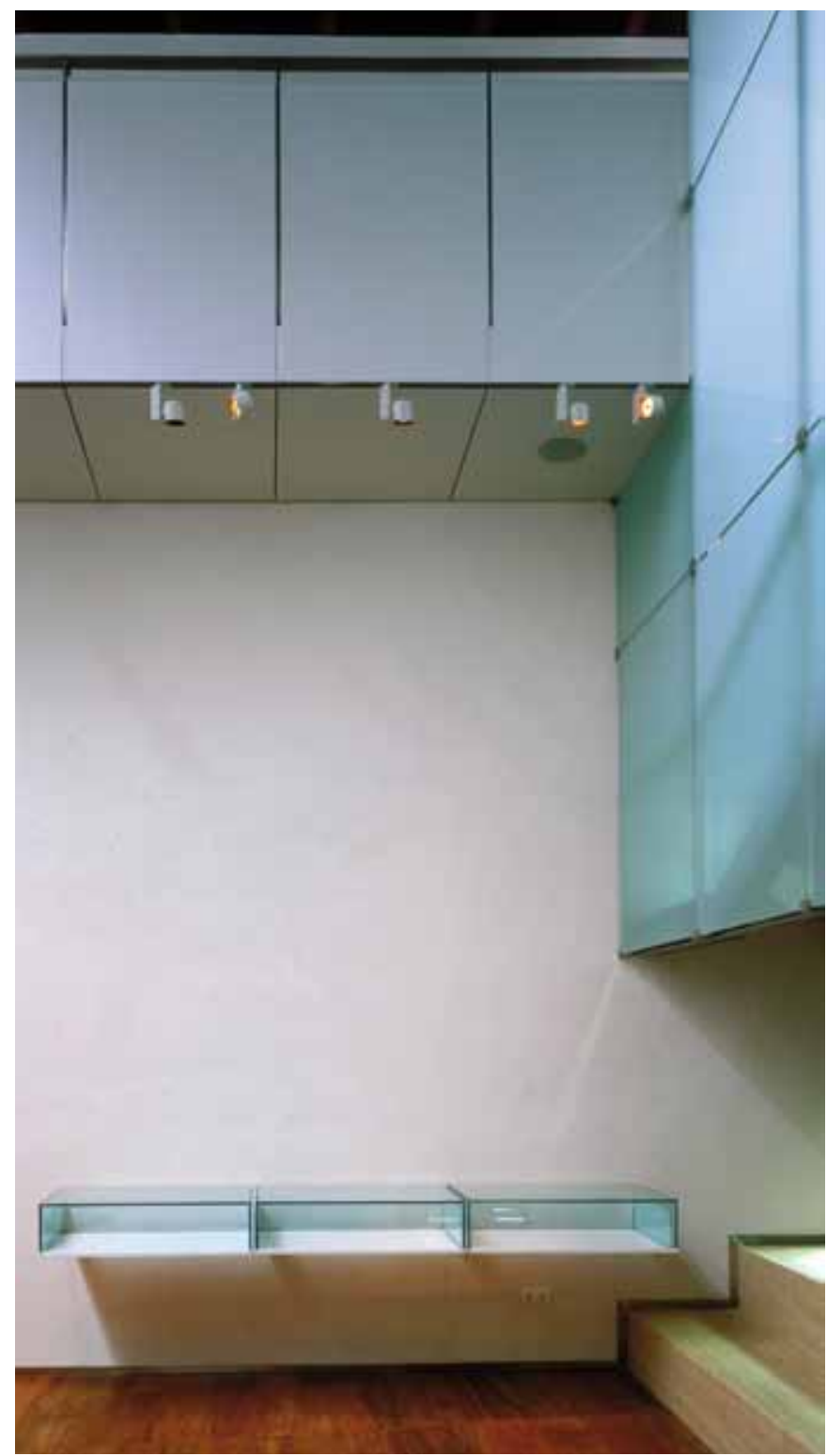

Pasarela y vitrina expositiva. Foto: Fernando Alda

metros de la fachada y del inservible castillete de la casa contigua que asoma por encima del lienzo sur de la Puerta cuando se la contempla desde cierta distancia. Estamos hablando, en definitiva, de la restauración del paisaje histórico de Carmona.

Ahora bien, si el paisaje y sus extraordinarios valores fueron el gran argumento que impulsaba la restauración de la Puerta de Córdoba y que nos llevaba a plantear acciones más allá del propio edificio ¿cómo abordar la creación de un centro de visitantes en un lugar tan sensible?

Como arquitectos, nos gusta pensar que las estrategias del proyecto contemporáneo en el paisaje o en el seno de los grandes monumentos del pasado son múltiples y contingentes y no deben entenderse en sentido estricto con una vocación finalista, sino como un sistema de activación del proyecto, como una mediación entre la realidad y las ideas que podemos manejar en cada caso. 


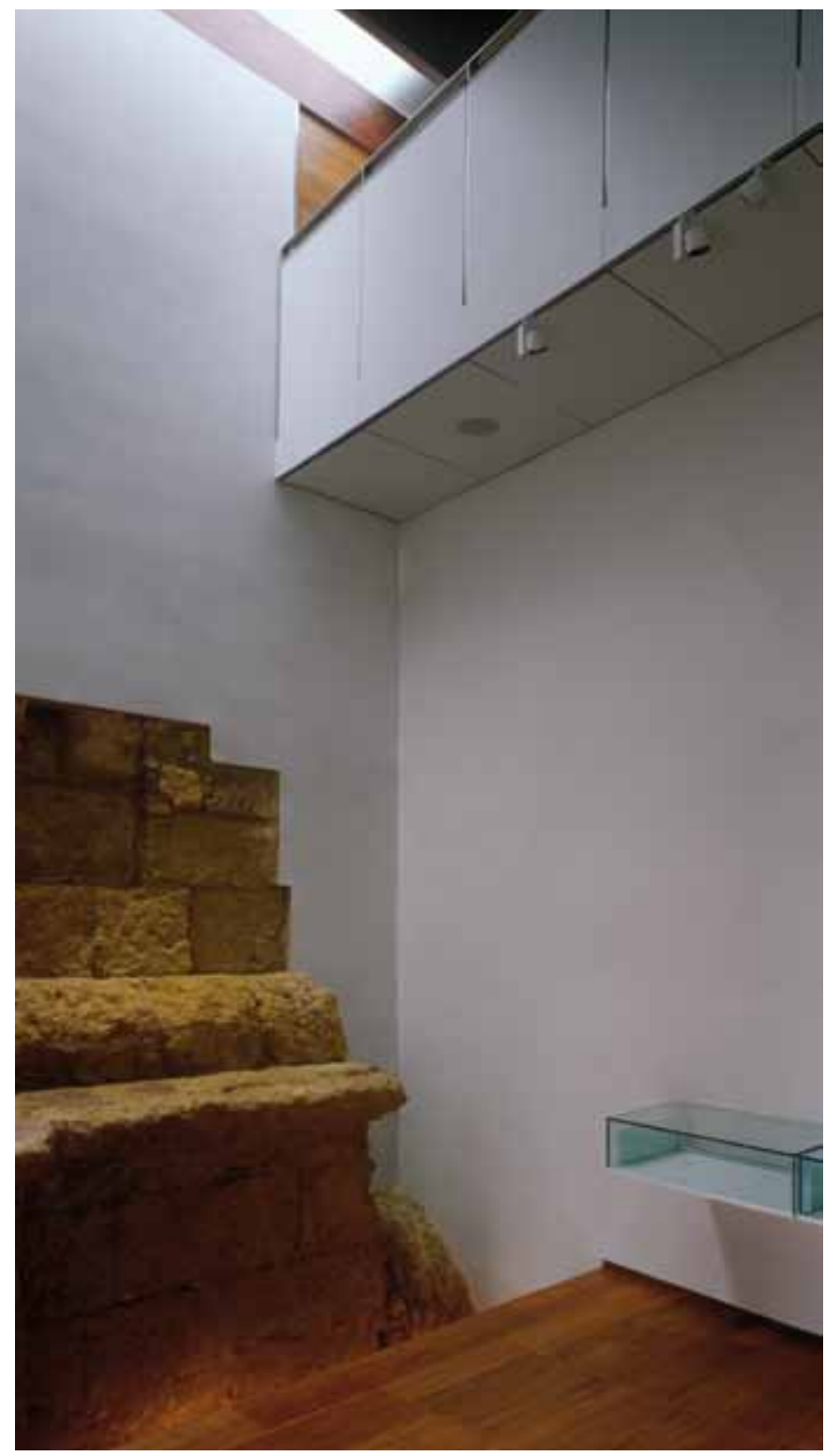

Galería superior de acceso al ático. Foto: Fernando Alda

La intervención en un paisaje cultural excepcional como el de Carmona encuentra sus argumentos tanto en el análisis de los valores históricos y paisajísticos del sitio como en la arquitectura antigua y en el programa de uso que debe satisfacer, que en nuestro caso consistía en disponer de un espacio abierto al visitante, didáctico y comunicativo, que explicitara aquellos valores.

La escalera de acceso al ático, también convertido en pequeña sala de exposiciones, se ubica en la posición más alejada de los restos del podio romano, separada de la sala de interpretación mediante una cortina de vidrio blanco destinada a matizar la relación de lo nuevo y lo antiguo, a introducir la luz difusa en el interior. Si la construcción del centro de visitantes ha permitido exhumar los restos más valiosos para desvelar un rico pasado, de forma inversa sobre la nueva arquitectura hemos colocado un velo traslúcido destinado a suavizar su relación con los restos musealizados. Al exterior la intervención es apenas perceptible

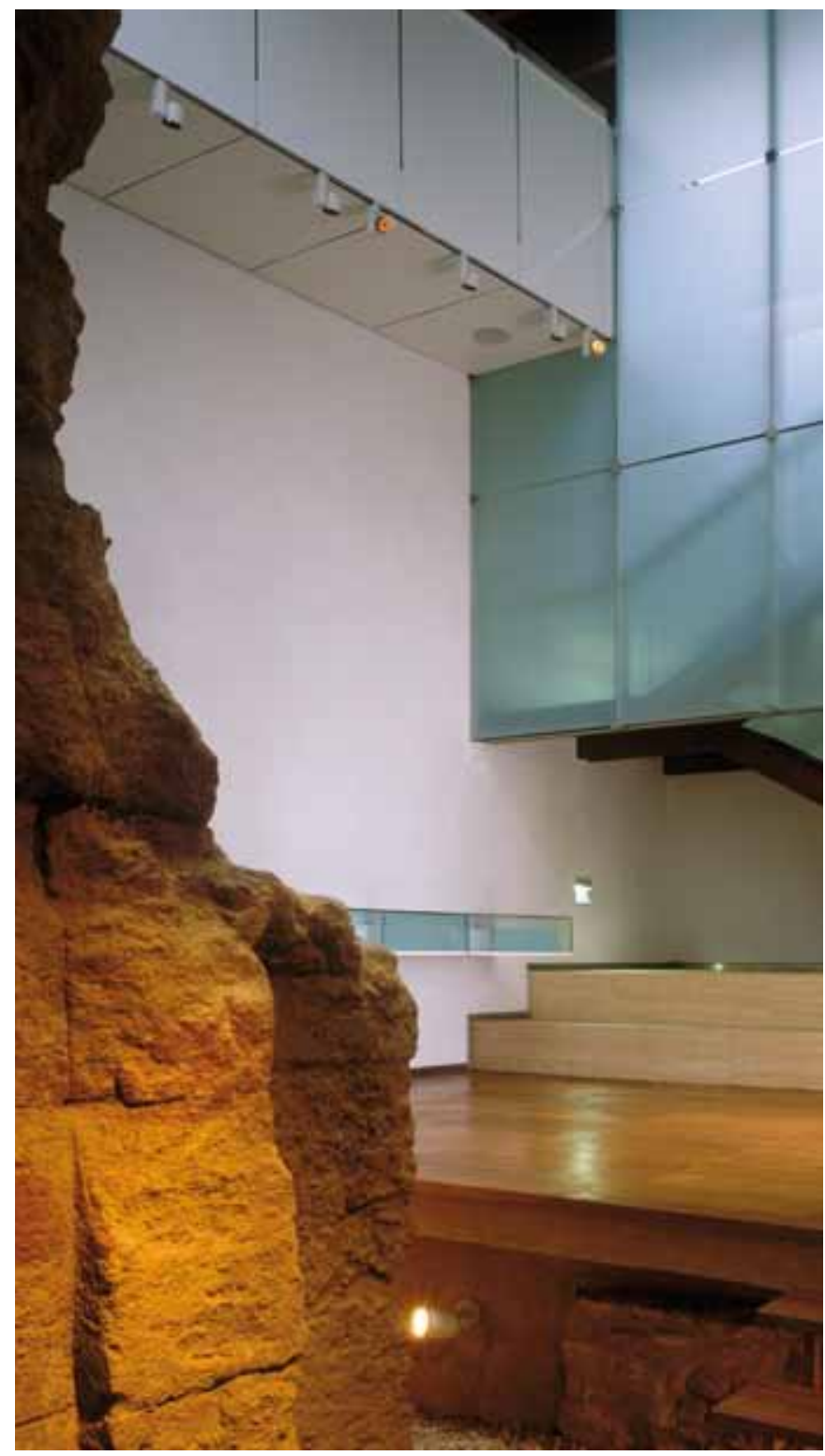

Vista del interior desde la Puerta Sur. Foło: Fernando Alda

tras el muro rojo preexistente en el que asoman sólo la puerta de entrada y el remate de la cubierta de cobre. La nueva arquitectura se oculta para ceder el protagonismo urbano al monumento, aunque sin renunciar a un progresivo descubrimiento de las estrechas relaciones que mantienen entre sí la Puerta y el Centro de Recepción en los niveles sucesivos que el visitante recorre, desde el nivel arqueológico original de la puerta romana hasta el hermoso paisaje circundante que puede contemplar desde las terrazas altas.

Ocultación como estrategia y como actitud que, desde la modestia y el deseo de diálogo con el presente que es todo patrimonio histórico, permite introducir un nuevo elemento sin agredir al edificio antiguo, una arquitectura blanca y matizada que contrasta sin estridencias con el color albero y la textura mate de la piel del monumento. Una caja silenciosa que se oculta para dejar hablar a la arquitectura y al paisaje de Carmona. 


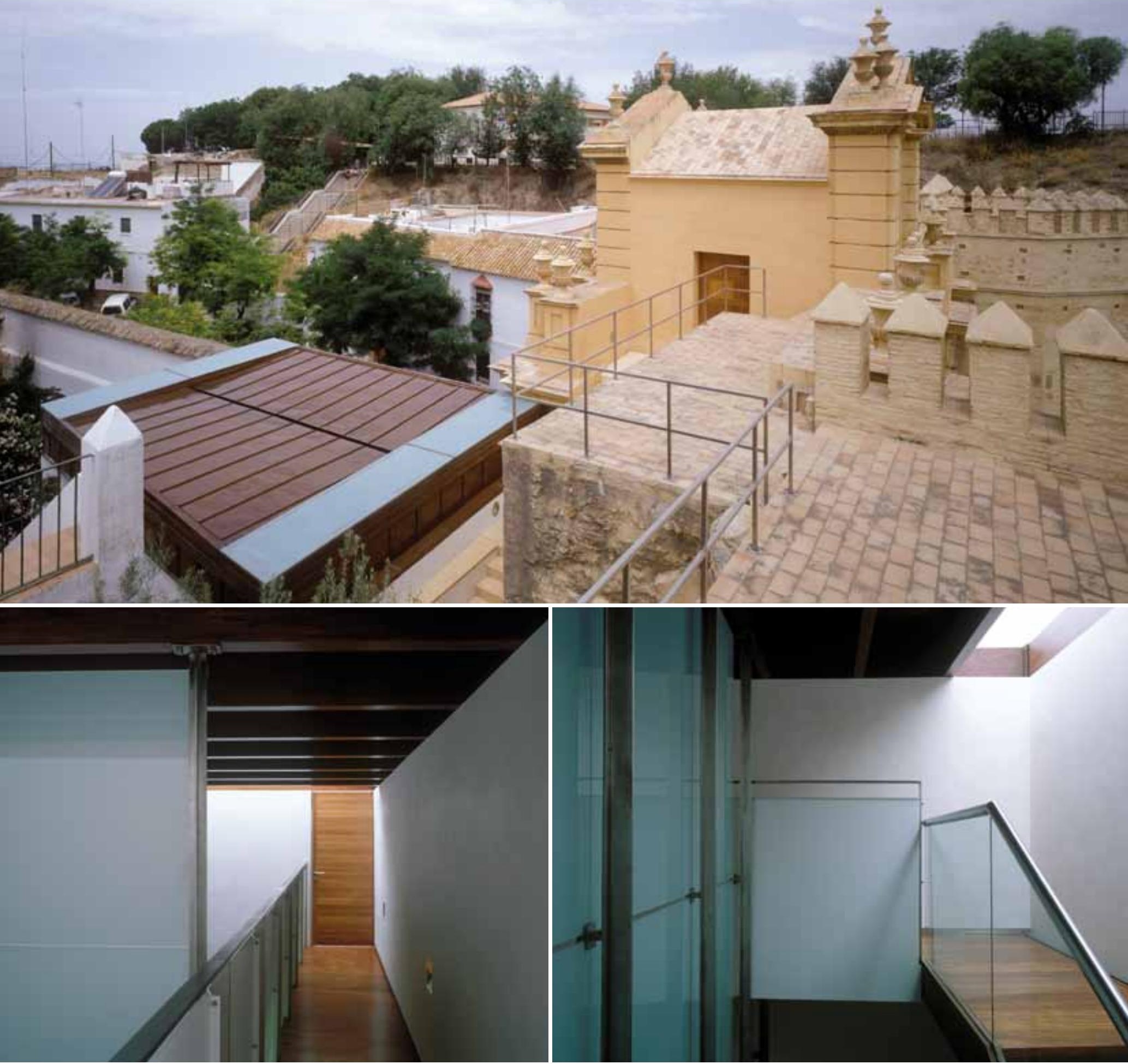

Vista general de las cubiertas (arriba) y la pasarela (abajo)

Fotos: Fernando Alda 


\section{Agradecimientos}

Los autores quieren expresar su gratitud a: Román Fernández-Baca, Director del IAPH que impulsó todas las fases de intervención; Maribel Montaño, Delegada Provincial de la Consejería de Cultura en los años del proyecto; Juan Antonio Fernández Naranjo, arquitecto Jefe del Departamento de Conservación de la Delegación Provincial de Cultura; Brooke Alexander, vecino del monumento; al Excmo. Ayuntamiento de Carmona; y a la Asociación Nacional de Amigos de los Castillos que reconoció la Intervención en la Puerta de Córdoba de Carmona con la Medalla de Oro a la Defensa, Difusión y Puesta en Valor 2007.

\section{Notas}

${ }^{1}$ Sobre los riesgos de tematización del patrimonio histórico ha reflexionado admirablemente lgnasi Solá-Morales (SOLA-MORALES, 1998).

${ }^{2}$ Una aproximación más detenida a la idea de musealización o museización que manejamos puede leerse en "Tomar partido pelas coisas" (TEJEDOR CABRERA, 2009), que toma el título del primer libro del poeta galo Francis Ponge (1942)

${ }^{3}$ Para más información, léase también GAVIRA BERDUG0, 2004.

${ }^{4}$ Para una información detallada sobre la restauración de la Puerta de Córdoba de Carmona puede consultarse el número especial de la revista $P H$ que documenta tanto las investigaciones como la obra realizada. En especial TEJEDOR CABRERA (2000). En el mismo número se presentó una primera aproximación al proyecto de un centro de visitantes que sirvió de base, con modificaciones sustanciales de volumen y materiales, al proyecto definitivo redactado en 2002 (TEJEDOR CABRERA; LINARES GÓMEZ DEL PULGAR, 2000).

\section{Bibliografía}

FERNÁNEZ LACOMBA, J.; CALVO LAULA, A. (1997) In Vandalia Carmona (Siete ensayos sobre la ciudad). Sevilla: Diputación de Sevilla, 1997

GAVIRA BERDUGO, M. (2004) Informe-memoria de Intervención Arqueológica en la Puerta de Córdoba (Carmona). Campaña 2004. Inédito

LERÍA, A. (editor) (1997) El Curioso Carmonense. Carmona: S\&C ediciones, 1997 (manuscrito original de 1787)

OJEDA CALVO, R. (2001) Nuevos datos sobre la Puerta de Córdoba en época romana. En Carmona romana: actas del II Congreso de Historia de Carmona: Carmona, 29 de septiembre a 2 de octubre de 1999. Carmona: Delegación de Cultura, Ayuntamiento de Carmona; [Sevilla]: Universidad de Sevilla, 2001, pp. 159-188

OJEDA CALVO, R.; PÉREZ PAZ, A. (2000) La Puerta de Córdoba como espacio museográfico y contenido museológico. PH Boletín del Instituto Andaluz del Patrimonio Histórico, n. ${ }^{\circ}$ 33, diciembre 2000, pp. 162-167

SOLA-MORALES, I. (1998) Patrimonio arquitectónico o parque temático. Loggia, n. ${ }^{\circ}$, 1998, pp. 30-35

SONTAG, S. (1996) Contra la interpretación. Madrid: Santillana, 1996, pp. 38-39 TEJEDOR CABRERA, A. (2000) La Restauración de la Puerta de Córdoba en Carmona: del proyecto a la obra. PH Boletín del Instituto Andaluz del Patrimonio Histórico, n. ${ }^{\circ} 33$, diciembre 2000, pp. 140-150

TEJEDOR CABRERA, A. (2009) Tomar partido pelas coisas. RBD.APP. 0 poder da ideia. Lisboa: Insidecity, 2009, pp. 48-71

TEJEDOR CABRERA, A.; LINARES GÓMEZ DEL PULGAR, M. (2000) La Musealización de la Puerta de Córdoba. Proyecto de un centro de recepción de visitantes. PH Boletín del Instituto Andaluz del Patrimonio Histórico, n. ${ }^{3} 3$, diciembre 2000, pp. 158-161

\section{FICHA TÉCNICA}

\section{Proyecto}

Centro de visitantes Puerta de Córdoba

Ubicación

Carmona (Sevilla, España)

\section{Arquitectos}

Antonio Tejedor Cabrera, Mercedes Linares Gómez del Pulgar

\section{Colaboradores}

Pedro Lobato Vida, Rafael Callejas Martín, Mohamed Zghary,

María González García, Javier Silgado Rodríguez, arquitectos

\section{Dirección de obra}

Antonio Tejedor Cabrera

Dirección de ejecución

Victor Baztán Cascales

\section{Arqueología}

Reyes Ojeda Calvo (IAPH), Marco A. Gavira Berdugo

\section{Empresa constructora}

SANOR S.A.

\section{Restauración de piedra \\ Antonio Martín}

\section{Fechas de proyecto y obra}

Proyecto: abril 2002

Final de obra: mayo 2005

Inauguración: octubre 2005

\section{Propiedad}

Ayuntamiento de Carmona

\section{Financiación}

Consejería de Cultura de la Junta de Andalucía

\section{Presupuesto de obra}

$212.500 €+$ IVA

\section{Fotografías}

Fernando Alda

\section{Maqueta}

Jacinto Gómez 


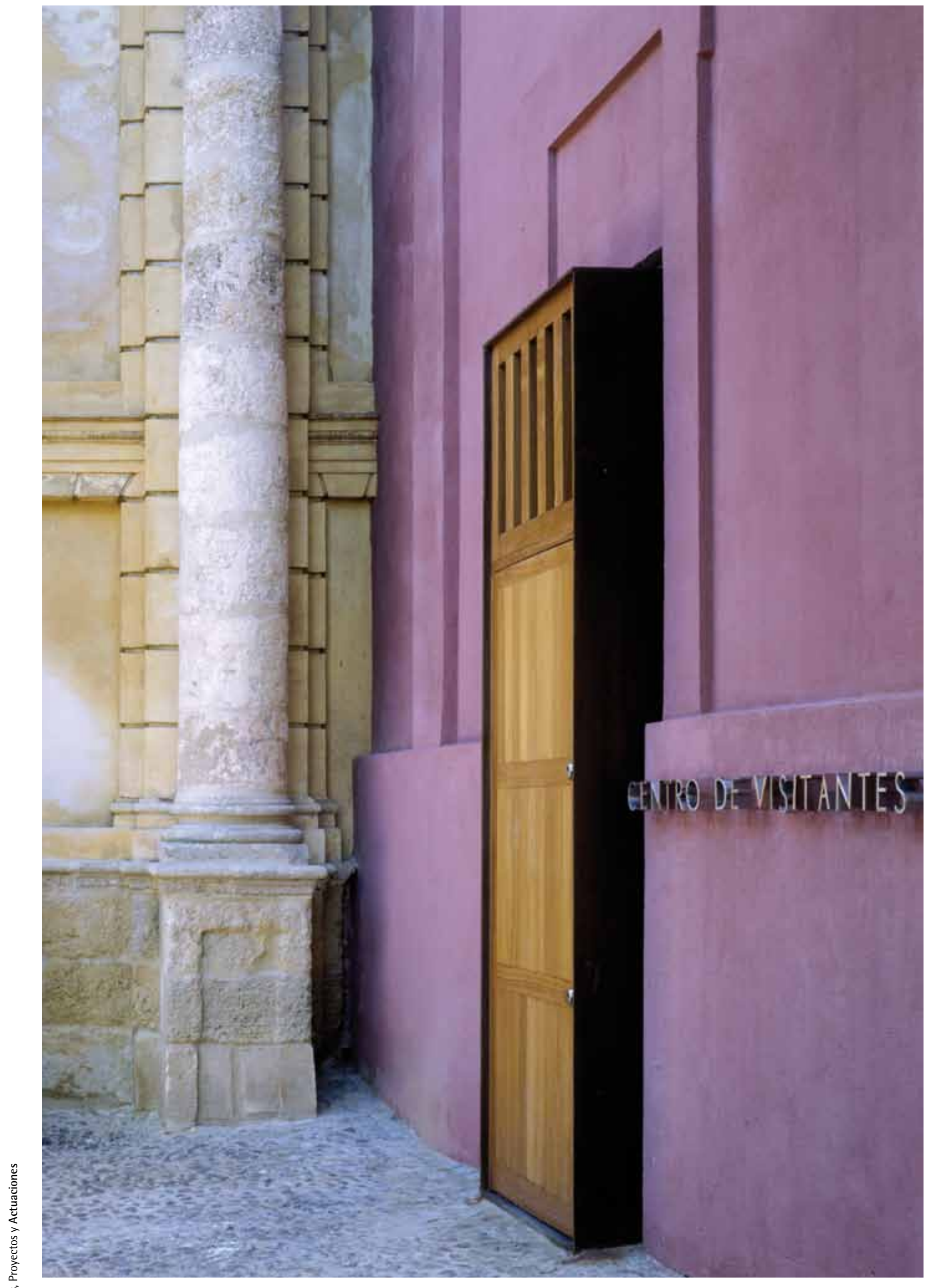

Puerta de acceso al centro de visitantes. Foto: Fernando Alda 


\section{DEL ESPACIO URBANO A LA HABITACIÓN DE LA MEMORIA DE LA CIUDAD}

Yago Bonet Correa, arquitecto

Pocas ocasiones se presentan al arquitecto, fuera de los estudios teóricos, de diseñar en un solo lugar las diferentes escalas proyectuales que permiten dotar al conjunto de una coherencia, produciendo al contemplar la obra terminada el especial placer de la unidad.

Este es el caso de la restauración de la Puerta romana de Córdoba de la ciudad de Carmona (proyecto 1996-obra 2000) y el centro de interpretación o de visitantes de la ciudad (proyecto 2002-obra 2005) un pequeño museo de $50 \mathrm{~m}^{2}$ que explica la memoria de ese lugar de la ciudad, un delicado espacio arquitectónico contemporáneo de vanguardia, que contiene desde los pequeños objetos diseñados del equipamiento museográfico, al fragmento de la fachada interna de la puerta romana como origen e historia del espacio urbano.

Ambas obras están intimamente ligadas fisica y conceptualmente, a pesar de estar realizadas en dos etapas de distinta naturaleza. La primera, la restauración, consolida, limpia y, a la vez, no borra la propia historia. Cuidadosamente incluye la reconstrucción de finales del siglo XVIII realizada por el arquitecto José Echamorro que, aunque dista de las hipótesis arqueológicas científicas más recientes, constituye un hermoso ejemplar culto de su época.

El gran acierto de la nueva restauración realizada por el arquitecto Antonio Tejedor reside en el conocimiento y la comprensión del significado del conjunto urbano y de la sensibilidad de interpretación que pone al realizar el proyecto, como diria Aldo Rossi "un dificil equilibrio entre la realidad ciertamente precaria de los viejos asentamientos y nuestro proyecto, nuestra alternativa".

Tejedor aborda su trabajo de un modo riguroso en colaboración con el Instituto Andaluz del Patrimonio Histórico, que se ocupó de los estudios científico-técnicos y de las campañas arqueológicas. Este punto de salida lo optimiza en la consolidación y en la limpieza, no sólo en su sentido físico sino sobre todo conceptual, que hacen que el proyecto de restauración y el proyecto de intervención del centro de visitantes sean un todo unitario que recupera el monumento y el espacio urbano habitable que abarca el entorno previo extramuros, de un gran significado territorial.

Con la misma naturalidad que tienen las capillas u oratorios de la ciudad, el centro de visitantes pasa casi desapercibido para los ojos profanos, debido a que el carácter esencial del proyecto lo integra de un modo intemporal como si hubiera existido siempre.

La caja que forma el espacio del centro de visitantes se cobija tras la tapia existente tan sólo rasgada por la puerta y acentuada por el rótulo; el interior sin ninguna ventana, solo se ilumina a través de la puerta cuya luz rebota en el suelo y la de dos lucernarios estrechos de débil luz opalina rasgados a lo largo de los extremos: sobre el muro romano y en el otro detrás de la cortina de vidrio sobre las escaleras, generándose con este sistema, una atmósfera en penumbra con claro-oscuros que agranda el espacio; recuperando para esta arquitectura contemporánea el ambiente de frescor de la tradición andaluza musulmana y barroca .

Lo más gratificante del disfrute de esta obra es la sensación de percibir de nuevo la textura y la continuación de la fachada de la cara de intramuros de la puerta romana y, a la vez, recuperar su cota arqueológica, lo cual permite a través de este fragmento de muro originalmente exterior leer la verdadera dimensión que tenía el monumento romano. De este modo la caja arquitectónica transfigura su contenido interior, introduciendo en ella la percepción del espacio urbano de dos mil años antes, convirtiéndose en lo que denominariamos la habitación de la memoria de la ciudad.
Esta operación conceptual del proyecto, en la que el espacio arquitectónico diseñado cerrado y denso se rasga y se transforma en un nuevo espacio urbano accesible al público, como un camino iniciático del conocimiento de la historia del lugar y, al mismo tiempo, también camino o tránsito que conduce de nuevo al espacio abierto. Y no es sólo una metáfora, ya que tras la pantalla de vidrio que velan unas escaleras, se inicia un pasillo que finaliza en una puerta que retorna al visitante de nuevo al exterior en un plano más alto. Desde este plano, a través de una escalinata de piedra, se asciende a la azotea de la torre romana, que permite contemplar los tejados de la ciudad, el propio monumento y el paisaje.

El centro de visitantes o de interpretación del lugar no sólo aporta el conocimiento de la memoria de la historia del lugar con su contenido didáctico sino también, al mismo tiempo, relaciona la ciudad y el territorio al proporcionar nuevos puntos de visualización y de comprensión de ambos, generando un especial atractivo al lugar, constituyéndose como un punto "sacro" de lo profano: la habitación colectiva de la memoria del espacio urbano.

Es necesario felicitar, desde la perspectiva de la cultura arquitectónica, al Instituto Andaluz del Patrimonio Histórico por haber confiado este proyecto riguroso a unos arquitectos que han valorado la función primordial de conservar el patrimonio, de no distorsionar el conjunto histórico y al mismo tiempo de incorporar a él la arquitectura actual, en cuyo diseño se aprecia desde los delicados detalles de las urnas museográficas, los elementos interiores de las mamparas y barandas al pavimento exterior urbano.

La restauración de la Puerta de Córdoba y el nuevo centro de interpretación son un magnífico ejemplo de intervención arquitectónica que redefine el lugar como un espacio más vital y conserva el límite nordeste de la preciosa ciudad de Carmona. 